\title{
Carbon Nanotube Membranes: Synthesis, Properties, and Future Filtration Applications
}

\author{
Md. Harun-Or Rashid and Stephen F. Ralph * \\ School of Chemistry, University of Wollongong, Northfields Avenue, Wollongong 2522, Australia; \\ mhor972@uowmail.edu.au \\ * Correspondence: sralph@uow.edu.au; Tel.: +61-242-214-286
}

Academic Editor: Yuan Chen

Received: 25 February 2017; Accepted: 24 April 2017; Published: 1 May 2017

\begin{abstract}
Over the course of the past decade, there has been growing interest in the development of different types of membranes composed of carbon nanotubes (CNTs), including buckypapers and composite materials, for an ever-widening range of filtration applications. This article provides an overview of how different types of CNT membranes are prepared and the results obtained from investigations into their suitability for different applications. The latter involve the removal of small particles from air samples, the filtration of aqueous solutions containing organic compounds and/or bacteria, and the separation of individual liquids present in mixtures. A growing number of reports have demonstrated that the incorporation of CNTs into composite membranes confers an improved resistance to fouling caused by biomacromolecules and bacteria. These results are discussed, along with evidence that demonstrates it is possible to further reduce fouling by taking advantage of the inherent conductivity of composite membranes containing CNTs, as well as by using different types of electrochemical stimuli.
\end{abstract}

Keywords: carbon nanotubes; buckypapers; fouling; permeability; pervaporation; desalination

\section{Introduction}

Ever since their (re)discovery by Sumio Iijima in 1991, carbon nanotubes (CNTs) have attracted enormous attention from academia and industry, because of their unprecedented mechanical, electrical, and thermal properties [1-3]. An immense range of potential applications have been proposed for $\mathrm{CNTs}$, including high-strength conductive composites, field emission displays, hydrogen storage devices, and sensors [4-7]. In addition, there has been growing interest in using CNTs to develop the next generation of membranes, which exhibit high flux and selectivity, and are resistant to fouling [8]. This has been motivated in part by the observation that the internal diameters of CNTs are comparable in size to those of many small molecules, which raises the prospect of size-based exclusion and the separation of chemical compounds [6]. Early investigations performed using molecular dynamics simulations indicated that the transport of gas and water molecules through the central channels of individual CNTs would be extraordinarily fast, owing to their extremely smooth, defect-free walls $[9,10]$. These predictions were supported by the results of experimental studies, which showed that the rates of the transport of gases and liquids through membranes composed of aligned CNTs were exceptionally fast $[7,11]$. A number of studies have been conducted in order to shed light on the reasons for the high degree of permeability exhibited by aligned CNT membranes [12-15]. The smoothness of the internal walls of the nanotubes was concluded to be an important factor, as this results in low levels of friction with neighbouring water molecules. Another factor was the very narrow diameter of the nanotubes. This was believed to facilitate formation of long chains of water molecules held together by unusually strong hydrogen bonds, which can then pass freely and easily through the slippery internal cavities. 
The above results highlighted the potential of CNT membranes for filtration applications, and have provided the motivation for further exploration of this new class of membrane materials. This has been reinforced by the results of investigations into the cytotoxic properties of CNT membranes, which showed that these materials are less prone to biofouling than some conventional polymeric membranes, and exhibit increased membrane lifetimes by killing and removing bacterial and viral pathogens [16]. This review initially provides a short summary of the methods employed for preparing carbon nanotubes, as well as for facilitating their dissolution and subsequent incorporation into different types of membranes. It then focuses on the potential of buckypapers (BPs) and composite CNT materials for the increasing number of filtration applications required to satisfy the world's burgeoning need for pure water for domestic use and industrial applications.

\section{Production of CNTs}

The primary methods employed for synthesising significant quantities of single-walled carbon nanotubes (SWNTs) and multi-walled carbon nanotubes (MWNTs) are shown in Figure 1, and include arc-discharge, laser ablation, gas-phase catalytic growth from carbon monoxide (CO), and chemical vapor deposition (CVD) from hydrocarbons [17]. Two of the earliest and most widely used approaches have been arc-discharge and laser-ablation, however these are only suitable for producing relatively small amounts of CNTs. Furthermore the products obtained often contain significant amounts of impurities in the form of catalyst particles, amorphous carbon, and non-tubular fullerenes [17]. Purification procedures are therefore generally required in order to separate the nanotubes from undesirable by-products, prior to investigating their properties and potential applications.

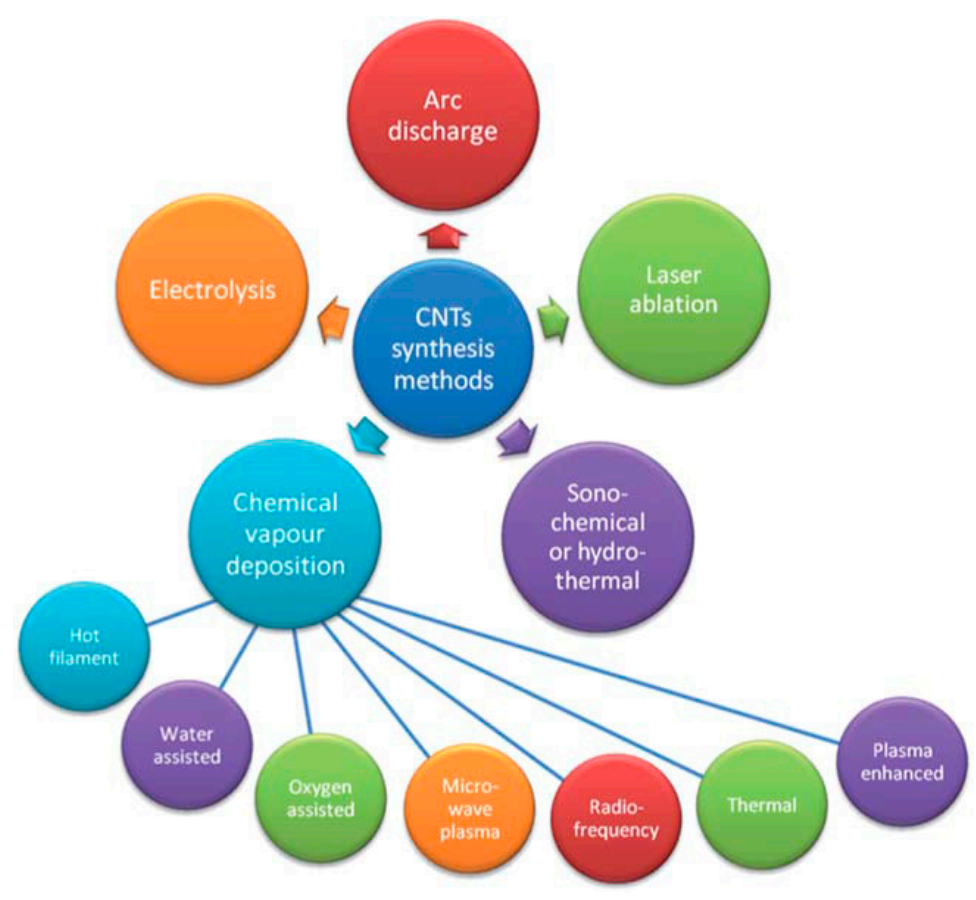

Figure 1. Currently used methods for synthesising carbon nanotubes (CNTs). Reproduced from Reference [17] with permission of the Royal Society of Chemistry.

The above limitations have motivated the development of gas-phase synthesis techniques, such as low temperature CVD methods $\left(<800{ }^{\circ} \mathrm{C}\right)$, during which nanotubes are formed by the decomposition of a carbon-containing gas. These gas-phase techniques are amenable to the continuous production of large quantities of nanotubes, since a flowing gas continually replenishes the source of the starting material. A further benefit of producing CNTs by CVD methods is that the purity of the resulting materials is generally quite high, thereby minimizing the need to perform subsequent purification 
steps [18]. For example, by using a modified CVD method, SWNTs with purities of up to $90 \%$ $(w / w)$ have been synthesized in the gas phase using $\mathrm{Fe}(\mathrm{CO})_{5}$ and $\mathrm{CO}$, in what has become known as the high-pressure carbon monoxide disproportionation (HiPCO) process [19]. Researchers from around the world have widely adopted the use of CNTs produced by the HiPCO process, owing to its comparatively low cost, the high purity of the resulting nanotubes, the use of relatively simple equipment, and the ability to produce nanotubes on a large-scale.

\section{Modification of CNTs}

While their extraordinary properties make CNTs attractive candidates for a diverse range of applications, their lack of solubility or processability in many common solvents has hindered their development for specific applications. CNTs can be dispersed in some solvents through the use of ultrasonic energy; however, precipitation immediately occurs in most cases when this process is interrupted. The covalent attachment of polar functional groups such as $\mathrm{COOH}, \mathrm{COH}, \mathrm{NH}_{2}$, and $\mathrm{OH}$ to the surfaces of CNTs, and the non-covalent adsorption of various functionalised molecules onto their surfaces, have both proven to be popular methods for overcoming their lack of solubility and for facilitating dispersion into solution [20].

The direct attachment of polar functional groups to CNTs can be readily accomplished using standard synthetic chemistry methods, and provides opportunities for carrying out a range of further reactions with CNTs, including silanation, esterification, alkylation, and thiolation [20-22]. In addition, chemically functionalised CNTs can participate in strong interfacial bonds with many polymers, enabling the preparation of CNT nanocomposites that exhibit exceptional mechanical properties. Despite these advantages, a drawback of the covalent functionalisation approach to surface modification, is that the reactions employed are generally accompanied by a change of hybridisation of the carbon atoms from $\mathrm{sp}^{2}$ to $\mathrm{sp}^{3}$. This results in a loss of $\pi$-conjugation, and consequently, in a reduction in the electrical conductivity of the nanotubes. As a result, considerable effort has been devoted to developing alternative methods for solubilising CNTs that are convenient to use, and which have a minimal impact on their structure and properties.

The non-covalent modification of the surfaces of CNTs involves the adsorption of surfactant or polymeric molecules. It is an attractive alternative method for enhancing the solubility, and therefore, the ability to process CNTs into useful materials, as it does not compromise their physical properties. The dispersion of CNTs into solutions containing poly(phenylene vinylene) and polystyrene was attributed to the wrapping of the latter molecules around the tubes $[23,24]$. This led to the formation of supramolecular complexes held together by van der Waals and $\pi-\pi$ stacking interactions between the CNTs and aromatic rings within the polymer chains. A consequence of this was the weakening of the van der Waals interactions between the CNTs, which increased their ability to disperse into aqueous solution.

A number of studies have shown that a range of proteins, including bovine serum albumin and lysozyme, are also capable of forming stable aqueous dispersions of CNTs $[25,26]$. The use of protein dispersants is of particular interest due to their lack of toxicity compared to common surfactants, as well as their biocompatibility [26]. In addition, proteins contain a number of different types of reactive functional groups such as hydroxyls, carboxylic acids, amines and thiols, which provide sites for further surface modification of the nanotubes [27]. In the resulting aqueous dispersions, CNTs and protein molecules principally interact by an electrostatic mechanism, which is highly dependent on the solution $\mathrm{pH}[25,26]$.

Carbohydrates such as chitosan and gellan gum have also been shown to be highly effective under some circumstances at wrapping themselves around CNTs to facilitate the formation of aqueous dispersions [28]. For example, chitosan was found to be very effective at dispersing smaller SWNTs, enabling their separation from mixtures of nanotubes [29]. It was reported that the chitosan molecules wrap themselves along the nanotube axis, as shown schematically in Figure 2 [30]. Evidence for this 
conclusion was provided by transmission electron microscopy studies on individual nanotubes which had been coated with chitosan [30].

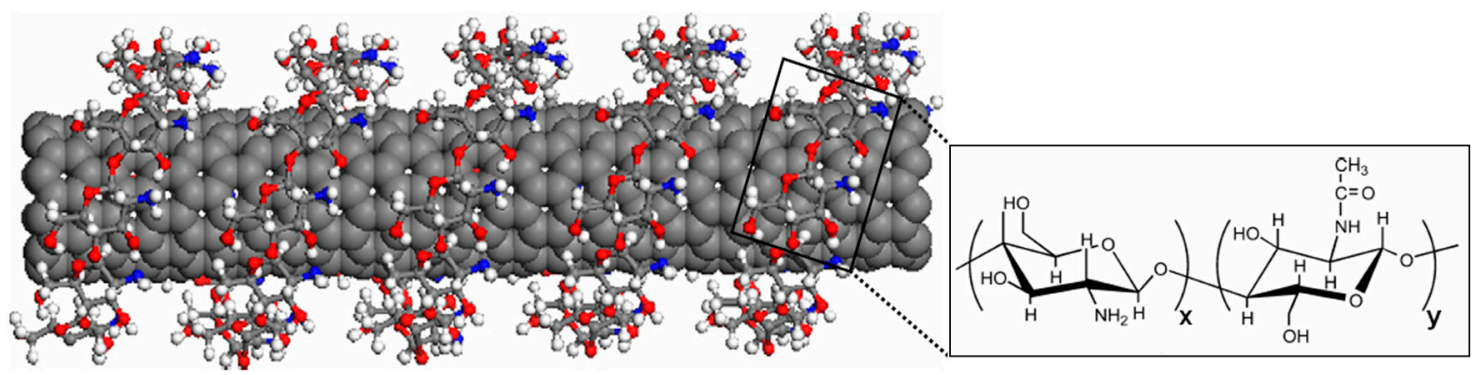

Figure 2. Schematic illustration of chitosan helically wrapping around the outside of a CNT. The structure of chitosan is also shown. Reproduced with permission from Reference [30]. Copyright Elsevier, 2007.

DNA has also been shown to be capable of dispersing CNTs into aqueous solution. This was attributed to the ability of the DNA bases to bind to the nanotubes through $\pi-\pi$ interactions, resulting in the exposure of the polar backbone of the nucleic acid to solvent molecules [31].

Due to their amphiphilic nature, surfactants have proven to be highly effective dispersing agents for CNTs [32-34]. It has been reported that surfactants with ionic, hydrophilic head groups, such as sodium dodecylsulfate (SDS), stabilise CNT dispersions by an electrostatic repulsion mechanism [35]. In contrast, polyoxyethylene octylphenylether (Triton X-100), a commonly used non-ionic surfactant, facilitates the dispersion of CNTs by attaching itself to individual nanotubes and using its hydrophilic moiety to form a large solvation shell around the assembly [36]. Triton X-100 and sodium dodecylbenzene sulfonate (SDBS) are both believed to participate in stronger interactions with the surfaces of nanotubes than SDS, and therefore, typically function as more effective dispersants, because of the presence of benzene rings in their structures that can facilitate $\pi-\pi$ stacking interactions.

Having access to methods that enable solutions containing dissolved CNTs to be prepared is critical if scientists are to harness their many extraordinary properties. However, it is also necessary to have methods for fabricating CNT dispersions into macroscopic structures such as films or membranes, which can then be incorporated into devices for specific applications. Two such fabrication processes are the production of aligned CNT membranes and the synthesis of buckypaper (BP) membranes. The following sections describe how these materials are prepared, along with their properties, and the results of studies that have examined their potential as membrane filtration media.

\section{Aligned CNT Membranes}

Aligned carbon nanotube membranes consist of highly ordered, vertically aligned arrays of individual CNTs (Figure 3). As a consequence, they possess a regular pore structure consisting of very narrow internal cavities within individual tubes, which are of the order of ca. $5 \mathrm{~nm}$ in the case of MWNTs [37]. This inner core diameter is similar to the size of many proteins and other biological macromolecules, which suggests that aligned CNT membranes could be suitable for a variety of ultrafiltration and nanofiltration applications [38]. An important feature of aligned CNT membranes is that the size of their pores can be precisely determined by controlling the size of the catalytic particles used during nanotube growth. This potentially provides a mechanism by which the selectivity of the membrane can be adjusted to suit a particular separation application. It is also possible to further fine-tune the molecular selectivity of these materials by covalently functionalizing the ends of the nanotubes with specific functional groups or molecules $[39,40]$.

Recently, it was also shown that it is possible to vary the diameter of the pores in an aligned CNT membrane between 38 and $7 \mathrm{~nm}$, by applying an external force perpendicular to the long axis of the nanotubes [41]. This resulted in the nanotubes being compressed together and an increase in the water 
permeability up to $30,000 \mathrm{~L} \cdot \mathrm{m}^{-2} \cdot \mathrm{h}^{-1} \cdot \mathrm{bar}^{-1}$, which is greater than what has been reported for any other CNT membrane. The membrane was also demonstrated to inhibit bacterial adhesion, suggesting that it may offer an advantage over other types of membranes by being less susceptible to biofilm formation and fouling.
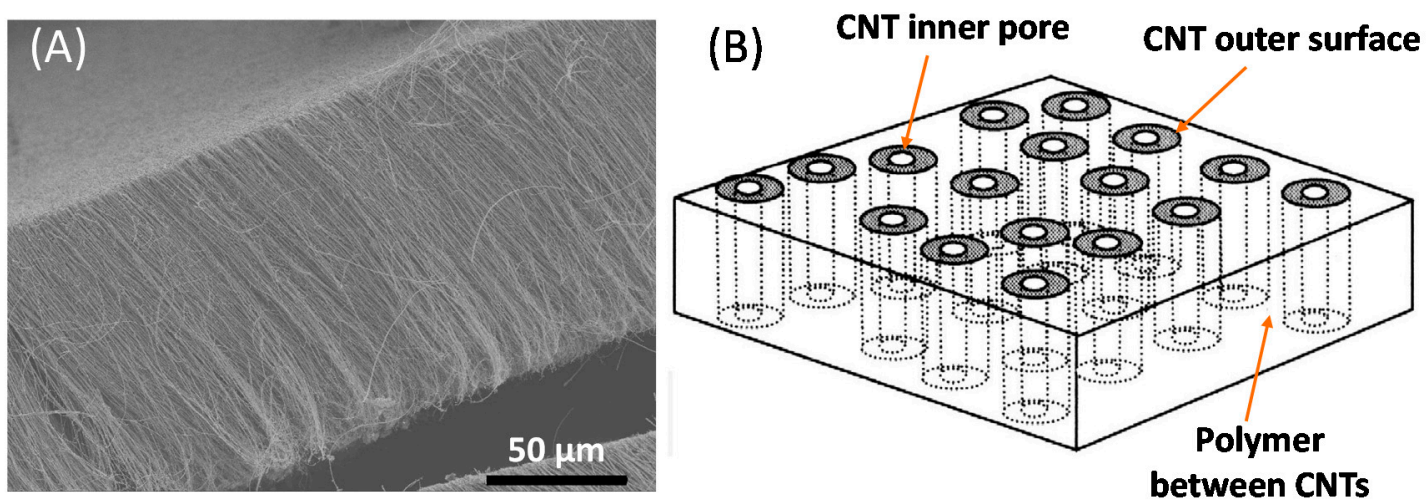

Figure 3. (A) Scanning electron microscope (SEM) image of a vertically aligned array of CNTs produced using a Fe-catalysed chemical vapor deposition (CVD) process; (B) schematic illustration of the structure of an aligned CNT membrane. From Reference [37]. Reprinted with permission from the American Association for the Advancement of Science.

Aligned CNT membranes can be prepared by embedding CNTs into a matrix, or by growing them directly onto a substrate, utilising a CVD process. If the aligned CNTs are grown onto the surface of a substrate, they must then be treated with a filler material such as polystyrene or silicon nitride, to fill in the interstitial voids between the individual CNTs [42,43]. The membrane composed of aligned CNTs is then removed from the underlying substrate, and the ends of the closed tubes are opened, for example, by oxidation using a water plasma. This exposes the entrances of the nanotubes to solvent, solute, and gas molecules. The above general approach was used by Majumder et al. to produce vertically aligned MWNT membranes with pore diameters of $7 \mathrm{~nm}$ that were four to five orders of magnitude more permeable towards water than a simple macroscopic membrane [42].

Free-standing aligned CNT membranes can also be produced without the use of a supporting material. The CNT forests that are produced in this manner are as highly aligned as those made by the procedure described above; however, the interstitial pores are not sealed using a polymeric binding agent or silicon nitride $[43,44]$. As a consequence, the final material can contain larger voids throughout its structure that extend up to tens of nanometres in diameter.

Aligned CNT membranes have been shown to selectively filter solute molecules present in aqueous solutions [7,11]. For example, aligned MWNT membranes with internal diameters of ca. $6.5 \mathrm{~nm}$ were found to allow the passage of $\left[\mathrm{Ru}(\text { bipy })_{3}\right]^{2+}$ (bipy $=2,2^{\prime}$-bipyridine) molecules and gold nanoparticles with average diameters of 2 and $5 \mathrm{~nm}$, respectively, but not larger gold nanoparticles with an average diameter of $10 \mathrm{~nm}$ [7]. In another study, researchers prepared macroscopic hollow cylinders composed of radially aligned MWNTs (Figure 4) [45]. These were shown to retain the heavier components of a hydrocarbon mixture, as well as bacteria and viruses present in contaminated solutions. More recently, Baek et al. compared the flux, rejection performance, and biofouling capabilities of aligned CNT membranes to those of a commercial UF membrane [46]. The aligned CNT membranes exhibited a water flux approximately three times greater than that of the UF membrane. In addition, they also showed a greater resistance to biofouling, including significantly lower levels of bacterial attachment [46]. In another study, Shaoyun et al. fabricated a new type of ultrafiltration (UF) membrane using vertically aligned MWNTs and polyethersulfone (PES) [47]. The orderly alignment of MWNTs inside the PES polymer matrix provided an ultra-efficient pathway for water transport, resulting in a flux of water that was three times greater than that exhibited by an MWNT/PES 
membrane featuring a random orientation of nanotubes. In addition, the water flux was 10 times greater than that of a pure PES membrane operating under the same conditions, and the aligned MWNT/PES membrane showed an improved rejection (95\%) of PEG molecules and anti-fouling properties [47].

\section{A}

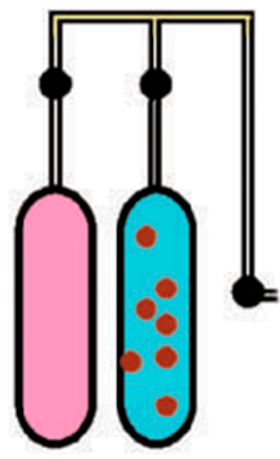

B

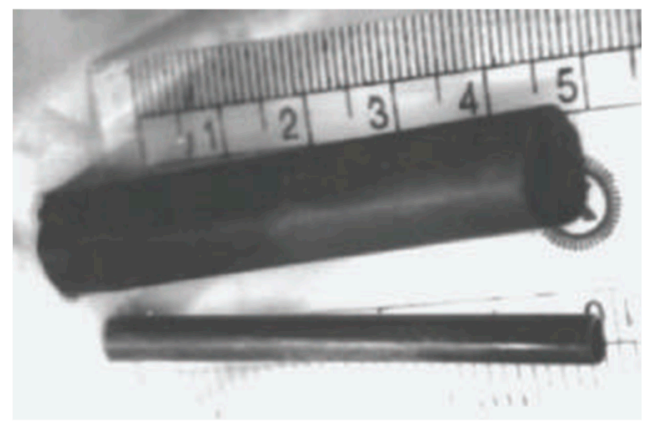

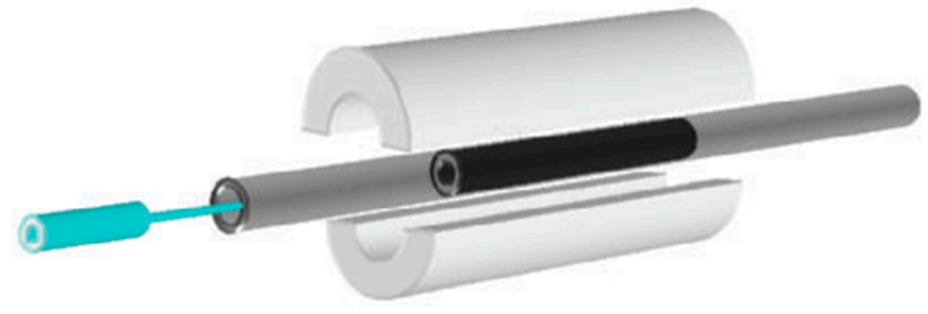

C

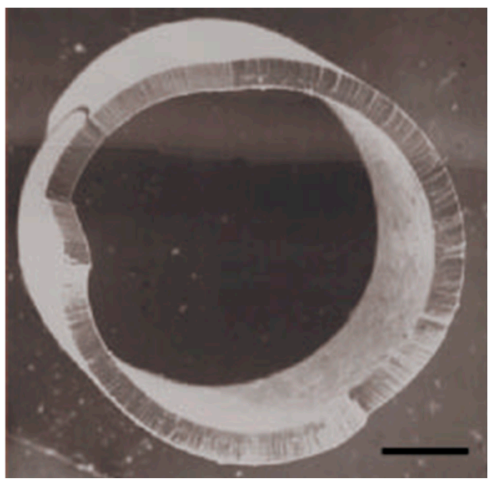

Figure 4. Production of a macro architecture consisting of aligned multi-walled carbon nanotubes (MWNTs), for use in filtration applications. (A) Schematic of the spray pyrolysis apparatus used for growing aligned MWNTs. The process consisted of a nozzle attached to a ferrocene/benzene solution supply used for releasing the solution into a quartz tube, mounted inside a temperature-controlled cylindrical furnace. A benzene/ferrocene solution was injected into the quartz tube, using argon as a carrier gas, and the temperature of the furnace then increased to $900{ }^{\circ} \mathrm{C}$; (B) Photograph of the bulk nanotube architecture produced by the above method; (C) SEM image of the aligned nanotubes with radial symmetry, resulted in a hollow cylindrical structure (scale $1 \mathrm{~mm}$ ). Reprinted by permission from Macmillan Publishers Ltd from Reference [45]. Copyright Nature Publishing Group 2004.

The presence of pores with very small and uniform diameters in aligned CNT membranes has also seen a significant amount of attention given to their potential for desalination applications. A number of recent reviews have highlighted the progress to date in this area, as well as that achieved through the use of composite CNT membranes [48-51]. While the permeability characteristics of aligned CNT membranes have been shown to be comparable to those of commercial UF and NF membranes, there are a number of drawbacks associated with their use. One of the most important is that the aligned forest of CNTs usually has to be removed from an underlying substrate, which can involve vigorous chemical etching methods using hazardous reagents such as hydrofluoric acid (HF). Another disadvantage with using aligned CNTs is that in order for them to act optimally as filtration media, their ends must be opened, which also requires harsh conditions such as plasma oxidation. Both steps are also complex to optimise and costly to perform. In addition, most aligned CNT membranes produced to date only have a relatively small surface area, require a lengthy fabrication process, exhibit 
a poor mechanical stability and low CNT packing density, and show little resistance to fouling [52,53]. In view of these issues, there has been significant attention devoted to producing CNT membranes by alternative, less complicated and hazardous procedures, and which can be readily scaled up as required.

\section{Buckypaper Membranes}

Buckypapers (BPs) (Figure 5a) are a simple type of membrane architecture that consists of a self-supporting, entangled assembly of CNTs [54,55]. BPs are often flexible materials; however, they also exhibit a significant degree of chemical and physical stability [6,56]. Due to their intrinsic thermal, electronic, and mechanical properties, BPs have been proposed for various applications including nanoactuators, sensors, radio frequency filters, artificial muscles, and cold-field emission cathodes [6,57-60]. They are typically synthesized from dispersions of CNTs, which are obtained by applying ultrasonic energy to samples containing nanotubes and a suitable dispersant. The filtration of these dispersions onto a support membrane, using either vacuum or positive pressure, then results in the formation of the BP $[56,61,62]$.
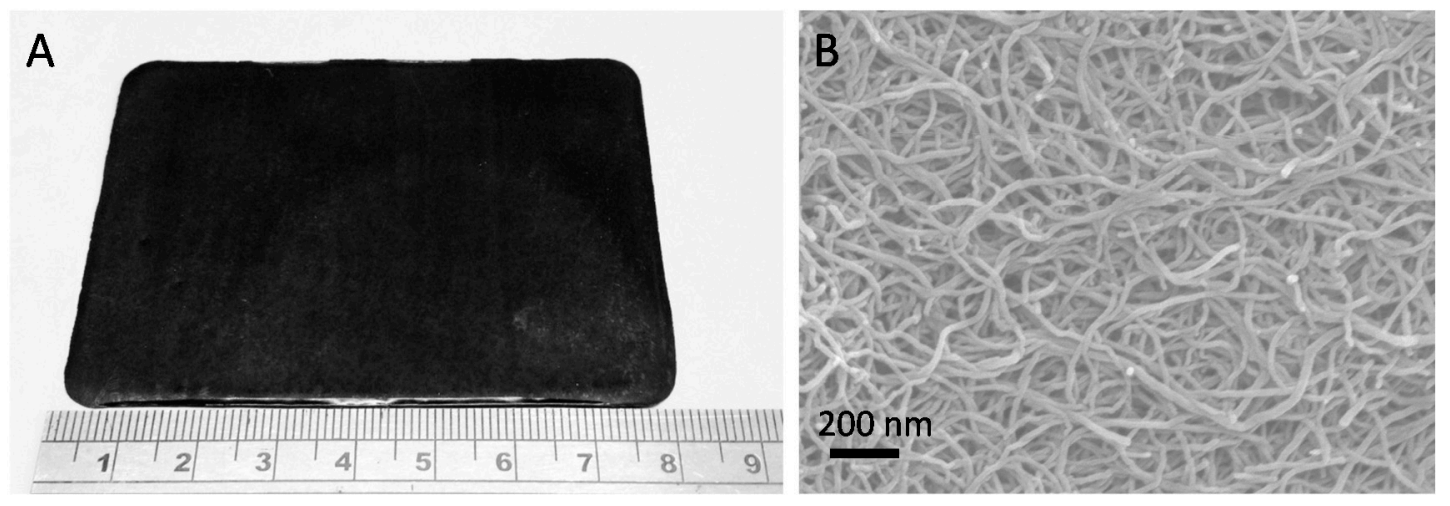

Figure 5. (A) Digital photograph of a MWNT buckypaper; (B) an SEM micrograph of a MWNT buckypaper (BP).

Due to their simple and inexpensive preparation procedures, it is generally possible to produce BPs on a larger scale than aligned CNT membranes. An examination of the surfaces of BPs using scanning electron microscopy reveals a highly disordered structure (Figure 5B), consisting of CNTs bound together by van der Waals forces and $\pi-\pi$ interactions [63]. The internal structure of BPs consists of a combination of small and large pores, which correspond to the spaces within and between bundles of CNTs, respectively. The pores in BPs contribute $60 \%-70 \%$ of their total volume, rendering them suitable as filtration media [61]. Despite this, only a small number of studies have investigated the filtration properties of BPs.

One reason for this is their poor mechanical properties, as BPs are often brittle due to weak connections between nanotube bundles. A method for overcoming this problem is to reinforce BPs by polymer intercalation $[61,64]$. For example, Coleman et al. showed that the infiltration of polyvinyl acetate, polyvinyl pyrrolidone, or polystyrene into BPs resulted in increases in Young's modulus, tensile strength, toughness, and strain to break values [64]. In addition, Boge et al. showed that the incorporation of biopolymers, including proteins and polysaccharides, into BPs composed of SWNTs can improve their mechanical properties [65]. Microanalytical data showed that some of the biopolymers were retained in the BP after they were prepared by vacuum filtration, most likely as a result of their ability to interact in a non-covalent fashion with the nanotubes [65].

Enhancing the mechanical properties of buckypaper membranes is also important because it lowers the risks that ensue from the release of individual CNTs into the environment. There have been many investigations into the biological consequences of exposure to CNTs, triggered in part 
because of the superficial resemblance of these materials to asbestos particles. These studies have shown that CNTs exert a range of effects, including the induction of oxidative stress, interference with cell signaling pathways, and membrane disruption [66-72]. As a consequence, it is of the utmost importance to ensure that even small numbers of CNTs do not break free from buckypapers, or any other type of CNT membrane. This risk can potentially be minimized by covalently linking the nanotubes to each other in a buckypaper or aligned CNT membrane, or to an underlying matrix in the case of a composite material.

\section{Filtration Applications}

\subsection{Filtration of Air Samples}

One of the first demonstrations of the potential of CNTs for filtration applications involved composite materials consisting of $2 \mu \mathrm{m}$ ultrathin MWNT BP films supported on cellulose filters [73]. Fine aerosol particles ranging between 50 and $500 \mathrm{~nm}$ in diameter were removed by the composite BP, with efficiencies that exceeded the standards set by the United States government for high efficiency particulate air (HEPA) filters [73]. Since the diameters of the nanotube fibres were much smaller than those of the aerosol particles investigated, it was concluded that the principal mechanism of rejection could not involve the Brownian diffusion of particles within the pores of the filter material. Instead, rejection was described as most likely being caused by the interception and inertial impaction of aerosol particles on the surface of the material, or, in other words, through the adsorption of aerosol particles. Owing to the high efficiencies demonstrated by their composite BPs, the authors suggested that they could also be used as filters for removing contaminants such as viruses from bioreactor feed streams.

In a more recent study, the suitability of an MWNT/ceramic composite membrane for air filtration applications was investigated [74]. A CVD method was used to prepare the composite filter by growing MWNTs on a porous alumina ceramic membrane. The ability of both the pristine ceramic membrane and the composite material to function as particulate filters was investigated using a sample of $\mathrm{SiO}_{2}$ with an average particle size of $296 \mathrm{~nm}$. Under the same conditions, the pristine ceramic membrane showed a retention rate of $79.88 \%$, while for the MWNT composite, it was $99.99 \%$ for the most penetrating particle size. These results showed that the composite membrane met the criteria for both HEPA and ultra-low penetration air filters, according to the specifications of the United States Department of Energy [74].

The authors of the above study identified five different mechanisms by which aerosol particles can be removed by air filters. In addition to the three mechanisms noted above, filtration can also be achieved through gravity settling and electrostatic deposition mechanisms. It was also noted by the authors that when the rate with which samples were passed across the filters was increased, that Brownian diffusion became less important as a removal mechanism owing to the aerosol particles spending less time in contact with the filtration material. Instead, the direct interception of particles became increasingly important under these conditions. The greater efficiency of the MWNT/ceramic material was attributed to its BET surface area being approximately two orders of magnitude greater than that of the unmodified ceramic membrane, as well as to the enhanced flow of the air samples over the CNTs. The former property in particular, was identified as being an important contributor to the greater performance of the composite filter, owing to the significantly enhanced opportunities for interactions with aerosol particles.

Experiments were also conducted to evaluate the antibacterial properties of both the pristine membrane and the MWNT composite. It was shown that the presence of the MWNTs strongly inhibited the propagation of E. coli, owing to inactivation of the cells [74]. These results demonstrated that the MWNT/ceramic composite membrane shows great promise for multifunctional air filtration applications. 
In an attempt to prepare high performing air filters, Nasibulin et al. developed an aerosol CVD synthesis method for preparing free-standing nanotube films [75]. These were prepared by first collecting SWNTs on a microporous filter $(0.45 \mu \mathrm{m}$ pore diameter $)$, and then dry transferring them to a flexible polyethylene terephthalate substrate. The free-standing SWNT films were found to be exceptionally good air filters, with a retention efficiency of $99.99 \%$ towards $11 \mathrm{~nm}$ iron aerosol particles. This ability was attributed to the high surface area of the SWNTs.

\subsection{Filtration of Bacteria}

Brady-Estévez and coworkers were among the first to demonstrate the antimicrobial properties of BPs, and their ability to efficiently remove bacteria and viruses from contaminated water samples [16,76]. During their early experiments, these authors examined BPs prepared from dimethylsulfoxide (DMSO) solutions containing SWNTs and no dispersant molecules [16]. The BPs were not removed from the underlying poly(vinylidene fluoride) (PVDF) support membrane they were deposited on, prior to evaluating their ability to remove E. coli and MS2 bacteriophage virus particles from water [16]. Filtration experiments showed that the majority of the bacterial cells were retained, while measurements of their metabolic activity indicated that only $6 \%$ of the E. coli cells remained metabolically active after retention (Figure 6). Exceptionally high viral removal capabilities were also shown by the hybrid SWNT/PVDF membranes [16]. Brady-Estevez and co-workers postulated that the highly effective antibacterial properties exhibited by SWNTs themselves were a result of their ability to elicit significant amounts of damage to cell membranes [77]. In a subsequent study carried out by the same group, it was shown that the ability of SWNTs to damage the membrane of E. coli was more pronounced that than of MWNTs [78]. Furthermore, membrane disruption was believed to occur as a result of direct contact with the CNTs, and was accompanied by changes to cellular metabolic activity, gene expression levels, and cell morphology. The length of SWNTs was shown to have an effect on their antibacterial activity, in experiments involving Salmonella typhimurium and aqueous suspensions of the nanotubes [76]. This was ascribed to the greater ability of longer SWNTs to aggregate with the bacterial cells, thereby providing more opportunities for causing cellular damage. In contrast, shorter SWNTs tended to accumulate with themselves more than the bacterial cells, thereby reducing their antibacterial potential.

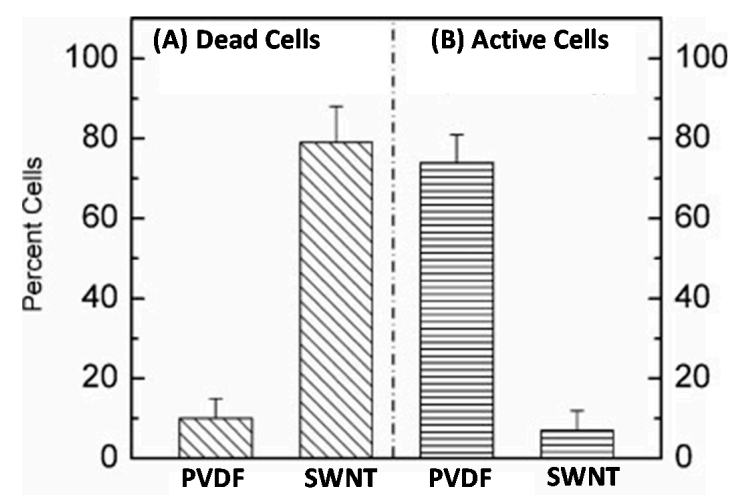

Figure 6. Inactivation and metabolic activity of E. coli cells retained on a SWNT/poly(vinylidene fluoride) (PVDF) composite filter and on a bare PVDF membrane filter: (A) Inactivation test results showing the presence of $E$. coli cells that are not viable; (B) metabolic activity test results indicating the presence of metabolically active E. coli cells. Adapted with permission from Reference [16]. Copyright John Wiley and Sons, 2008.

Recently, Sweetman et al. measured the permeability towards water, and determined the effectiveness for bacterial filtration, of self-supporting SWNT BPs prepared from dispersions containing macrocyclic ligands and antibiotics $[79,80]$. The incorporation of the macrocyclic ligands into the BPs 
in some instances resulted in large increases in water permeability compared to BPs prepared from dispersions of SWNTs also containing Triton X-100 [79]. The most dramatic increase in permeability was exhibited by SWNT/PTS (PTS = phthalocyanine tetrasulfonic acid) BPs, which displayed an average membrane flux of $2400 \pm 1300 \mathrm{~L} \cdot \mathrm{m}^{-2} \cdot \mathrm{h}^{-1} \cdot \mathrm{bar}^{-1}$. This value was almost 30 times greater than the average flux exhibited by SWNT/Trix BPs $\left(83 \pm 5 \mathrm{~L} \cdot \mathrm{m}^{-2} \cdot \mathrm{h}^{-1} \cdot \mathrm{bar}^{-1}\right)$, and was also greater than that for commercial $0.22 \mathrm{~mm}$ PTFE membranes $\left(1900 \pm 300 \mathrm{~L} \cdot \mathrm{m}^{-2} \cdot \mathrm{h}^{-1} \cdot \mathrm{bar}^{-1}\right)$ measured under the same conditions. Each of the above BPs was found to be $>99 \%$ effective for removing E. coli from aqueous suspensions [80]. This study therefore demonstrated that free-standing BPs can be just as effective for removing microbial contaminants from water supplies as the composite CNT materials investigated previously $[16,76]$.

Silver nanoparticles (Ag NPs) are currently amongst the most efficient and widely known antibacterial agents. This has been attributed to their capacity to damage protein and DNA molecules, interrupt electron transport chains, and disturb other cellular functions [81,82]. Significant effort has been devoted to determining whether silver nanoparticles themselves have any activity over what would be expected to result from the release of silver ions, which are themselves known to have antimicrobial properties. By carrying out experiments under conditions which rigorously excluded oxygen, and thereby prevent the formation of $\mathrm{Ag}(\mathrm{I})$ ions, it was shown that the antibacterial effects arise largely from metal ion release [81]. Silver nanoparticles have also been shown to elicit cytotoxic effects in human cell lines, in a manner dependent upon the size of the nanoparticles, and which is most likely attributable to the intracellular release of silver ions [83]. Recently, a new approach was used to synthesize a silver-doped MWNT composite, with the aim of fully utilizing the antibacterial properties of both MWNTs and silver [84]. The membranes prepared by this new approach showed a high water permeate flux, and strong antibacterial properties. Figure 7 shows how the amount of bacteria remaining in the filtrate varied as a function of time after passing through $\mathrm{Ag} / \mathrm{MWNT}$ composite membranes with different silver loadings. Membranes with a 10\% silver loading exhibited tremendous antibacterial properties. For example, almost $100 \%$ of bacteria were removed or killed by these membranes after just $1 \mathrm{~h}$ exposure.

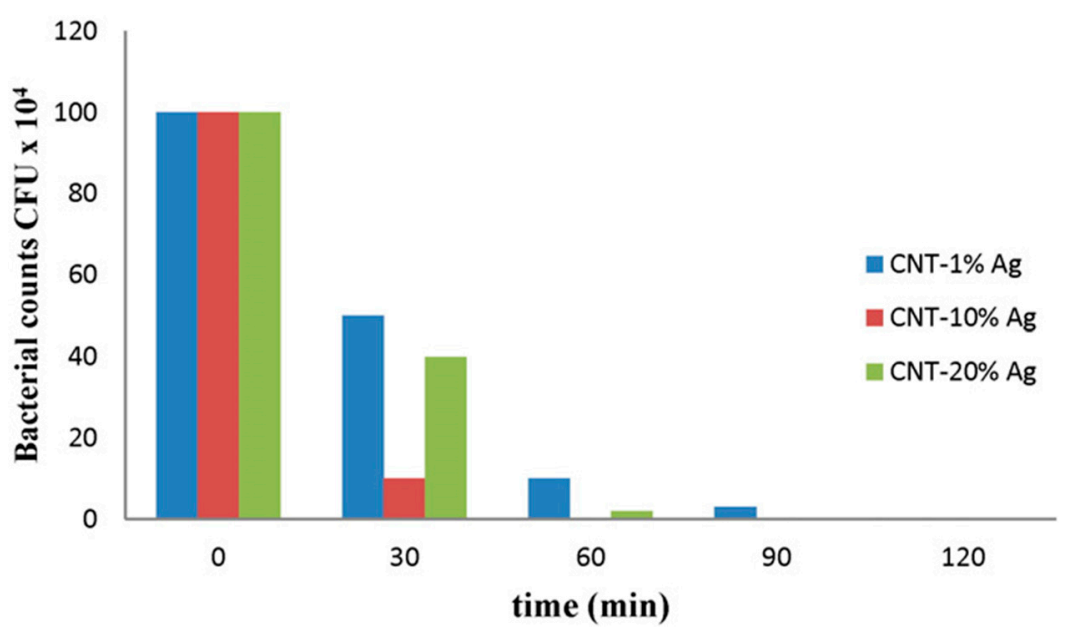

Figure 7. Effect of time on the amount of bacteria remaining in the filtrate (expressed as colony forming units (CFU)) after passage across Ag/MWNT membranes with different loadings of silver. Reproduced with permission from Reference [84]. Copyright Elsevier, 2015.

\subsection{Filtration of Gold Nanoparticles}

Self-supporting BPs prepared from dispersions of MWNTs in isopropyl alcohol have recently been successfully used as nanofilters for removing gold nanoparticles (Au NPs) from colloidal solutions [85]. An analysis of SEM images of the surfaces of the BPs (Figure 8a) revealed the presence of interstitial 
pores measuring $33 \pm 15 \mathrm{~nm}$ in diameter. Despite the presence of such large pores, the BPs were able to efficiently remove smaller gold nanoparticles. For example, a recovery efficiency of $100 \%$ was obtained when a colloidal solution containing $0.25 \mathrm{mM}$ Au NPs was used. Figure $8 \mathrm{~b}$ shows that the $\mathrm{Au}$ NPs were trapped on the surface of the BPs after filtration. These were shown by high-resolution transmission electron microscopy (HRTEM) to have an average diameter of $14.7 \pm 0.7 \mathrm{~nm}$ (Figure 8b). The complete rejection of Au NPs was highlighted by the total disappearance of the characteristic plasmon resonance peak at $520 \mathrm{~nm}$, in a UV-visible absorption spectrum of the permeate (Figure 8c).

The presence of gold nanoparticles on the surface of the BP in the SEM image shown in Figure 8b suggests that adsorption might have played a significant role in the mechanism of removal of the gold nanoparticles. However, the authors highlighted that exclusion was a result of the labyrinth of highly convoluted pathways that solvent and solute molecules were forced to take to traverse the membrane. In studies using smaller CdS nanoparticles, with an average diameter of $4.1 \pm 2.1 \mathrm{~nm}$, it was observed that some particles were excluded, whilst others were able to pass across the membrane. Based on estimations of the average diameters of the CdS nanoparticles in the feed and permeate solutions, it was concluded that the membranes exhibited a cutoff size of 4-5 nm. Size exclusion was also previously suggested to be the principal mechanism which determined whether gold nanoparticles of various sizes were able to pass through the pores present in aligned membranes composed of MWNTs [7].
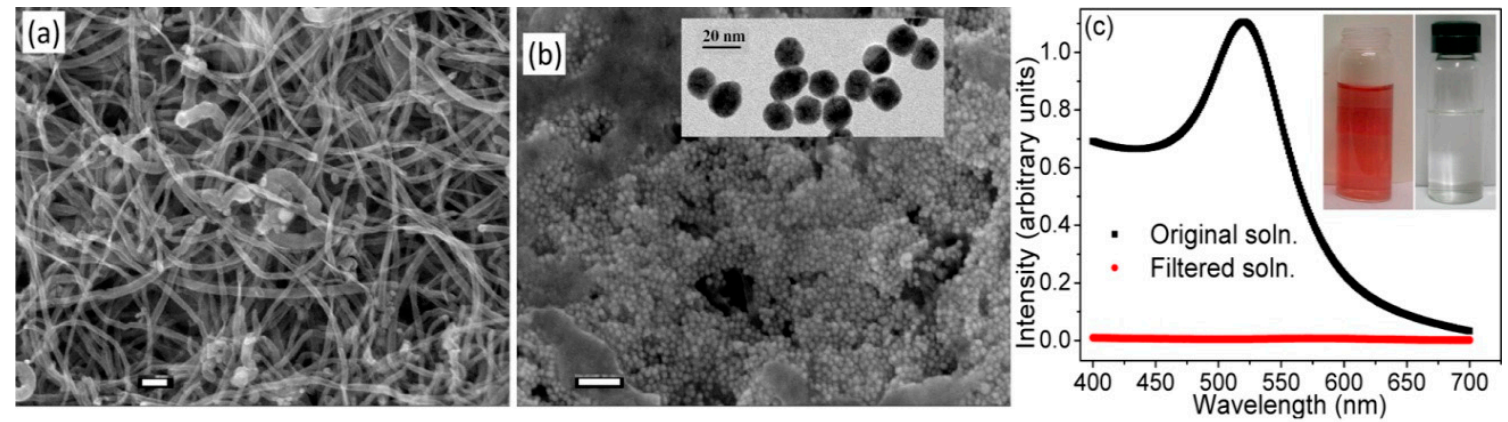

Figure 8. (a) SEM micrograph of the surface of a self-supporting MWNT BP prepared from a dispersion of MWNTs in isopropyl alcohol. Scale bar is $100 \mathrm{~nm}$; (b) SEM micrograph of the surface of the BP after filtration of gold NPs. Scale bar is $100 \mathrm{~nm}$. The inset is an high-resolution transmission electron microscopy (HRTEM) image showing the Au NPs; (c) UV-visible absorption spectrum of the colloidal solution of Au NPs before and after filtration through a MWNT BP. Reprinted with permission from Reference [85]. Copyright American Chemical Society, 2012.

\subsection{Filtration of Organic Compounds}

Further evidence that BPs may be useful for water purification applications was provided by Harris and co-workers [86]. Their studies involved BPs made from MWNT dispersions prepared in ethanol, without the assistance of a surfactant or other dispersant molecules. The BPs proved to be useful for the removal of humic acid from water samples, with recovery efficiencies $>93 \%$ being obtained. The authors demonstrated that carboxylic acid and hydroxyl functional groups were present on the surfaces of the CNTs, and concluded that the increased hydrophilicity that these functional groups bestow on the nanotubes was an important contributor to their effectiveness as filtration media.

Among the membrane separation technologies that are currently available, pervaporation is one of the most energy-efficient processes for separating azeotropic mixtures, isomers, or close-boiling mixtures that cannot be separated through conventional filtration processes [87]. Pervaporation is the separation of mixtures of liquids by partial vaporisation through a membrane. In this process, a feed solution consisting of a mixture of liquids is heated to the optimum operating temperature, and then brought into contact with the membrane. The permeate passes through the membrane and is continuously removed in the form of a vapour. This creates a concentration gradient across the membrane, which acts as an overall driving force for the process. To date, most studies have 
reported on the pervaporation of binary mixtures of water with either ethanol or ethyl tert-butyl ether (ETBE), using polymeric membranes or mixed matrix membranes [87-89]. For example, Choi et al. incorporated MWNTs into a PVA membrane, and then examined the suitability of the resulting composite for the dehydration of a water/ethanol mixture by pervaporation [87]. The efficiency of the membranes was observed to be affected by the amount of MWNTs present, with those containing $4 \%$ $(w / w)$ MWNTs determined to be the best performing materials of those examined.

Recently, it was reported that BPs can be used in a pervaporation process to separate organic compounds present in azeotropic mixtures in water [90,91]. In one such study, self-supporting MWNT BPs were used, which were prepared from dispersions of MWNTs in ethanol. The BPs were coated with a thin layer of PVA to form a new type of asymmetric MWNT/PVA membrane [90]. The PVA-coated BP membranes exhibited improved mechanical properties relative to pure PVA membranes. They were then used to dehydrate a multi-component azeotropic reaction mixture obtained from ethanol and tert-butyl alcohol (TBA), via a pervaporation process. When the purified MWNT/PVA membranes were used for pervaporation, they exhibited permeation fluxes and separation factors two and four times greater than those of a pure PVA membrane. This was believed to be due to the presence of hydrophilic groups on the oxidised MWNTs, and the existence of nanochannels within the pre-selective layer on the BP, which favoured the permeation of water molecules. It was also proposed that the MWNT/PVA BP could serve as a catalytic membrane in systems designed to separate the water and by-products of the etherification reaction (Figure 9) [90].

(A)

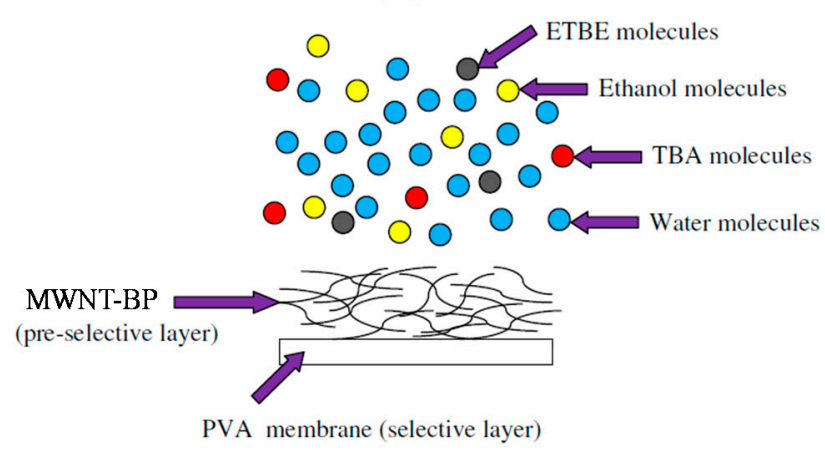

(B)

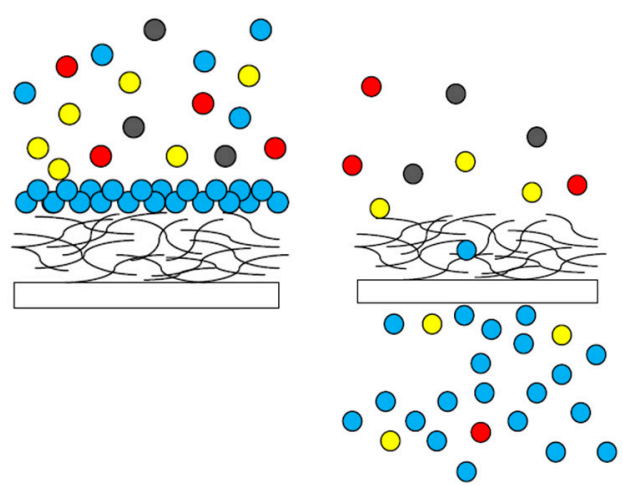

Figure 9. Schematic illustration of pervaporation of an azeotropic mixture. (A) Feed solution containing a mixture of ethyl tert-butyl ether (ETBE), tert-butyl alcohol (TBA), and ethanol; (B) intermediate; and (C) final stages of pervaporation using an MWNT/PVA BP. Reproduced with permission from Reference [90]. Copyright Elsevier, 2014.

Composite membranes containing nanotubes have often been used in investigations into the filtration properties of CNTs, owing to their superior mechanical properties compared to stand-alone membranes. An alternative method of endowing greater strength upon free-standing BPs, involved the preparation of a BP-supported ionic liquid membrane (SILM). The first step in the synthesis of this material involved blending 1-butyl-3-methylimidazolium tetrafluoroborate ([Bmim][BF $]$ ) with polyvinyl alcohol [91]. The resulting $[\mathrm{Bmim}]\left[\mathrm{BF}_{4}\right] / \mathrm{PVA}$ blend was then infiltrated into the interstitial pores of an MWNT BP. This resulted in the formation of a homogeneous BP/SILM composite material, which exhibited lower levels of resistance to mass transport, and enhanced thermal and mechanical stability. When the BP/SILM composite membrane was used in a pervaporation process to dehydrate an aqueous solution containing ethylene glycol, it displayed a significantly greater separation performance and permeability compared to other PVA membranes [92]. In addition, 
the BP/SILM composite membrane demonstrated a robust pervaporation performance over a period of $120 \mathrm{~h}$, further confirming its potential for industrial applications [91].

Organophosphates are among the most toxic substances synthesized to date, and are used as pesticides and nerve agents [93]. Recently, a new 'one-pot' methodology was developed for the rapid and straightforward fabrication of an enzymatically active MWNT BP to be used for organophosphate bioremediation [94]. This new type of BP was prepared from carboxylated MWNTs (MWNTs-COOH), which were ultrasonically dispersed in an aqueous solution containing Triton X-100. The resulting dispersion was then filtered under vacuum onto a cellulose support membrane to produce a composite MWNT BP membrane. Organophosphate hydrolase (OPH) was subsequently covalently immobilised onto the nanotube surface, to produce an enzymatically active OPH/MWNT BP. To demonstrate its potential for bioremediation, an aqueous solution of methyl paraoxon, a model oraganophosphate contaminant, was filtered using the OPH/MWNT BP. A significant decrease in the concentration of methyl paraoxon was achieved, which was ascribed to its in situ hydrolysis by the immobilised enzyme during the filtration process. This result provided proof of concept for a new generic approach to the design of bioactive BP scaffolds, which can be tailored for a range of applications from environmental remediation to biomedical devices.

In a recent study, a promising hybrid nanofiltration membrane was prepared using reduced graphene oxide (rGO) that had been intercalated with MWNTs. The resulting rGO/MWNTs were then loaded onto an anodic aluminum oxide microfiltration membrane via a vacuum-assisted filtration process [95]. This resulted in the preparation of a hybrid $\mathrm{rGO} / \mathrm{MWNT}$ membrane that was then used to purify drinking water by retaining Au NPs and a wide range of organic compounds, including dyes, proteins, organophosphates, sugars, and humic acid. The new hybrid membranes exhibited a high level of performance with respect to the rejection of fulvic acid from aqueous solutions (Figure 10) [95]. This ability could be observed qualitatively, with the yellow colour of the feed solution being converted into a clear and transparent permeate, as the fulvic acid was completely rejected by the membrane.

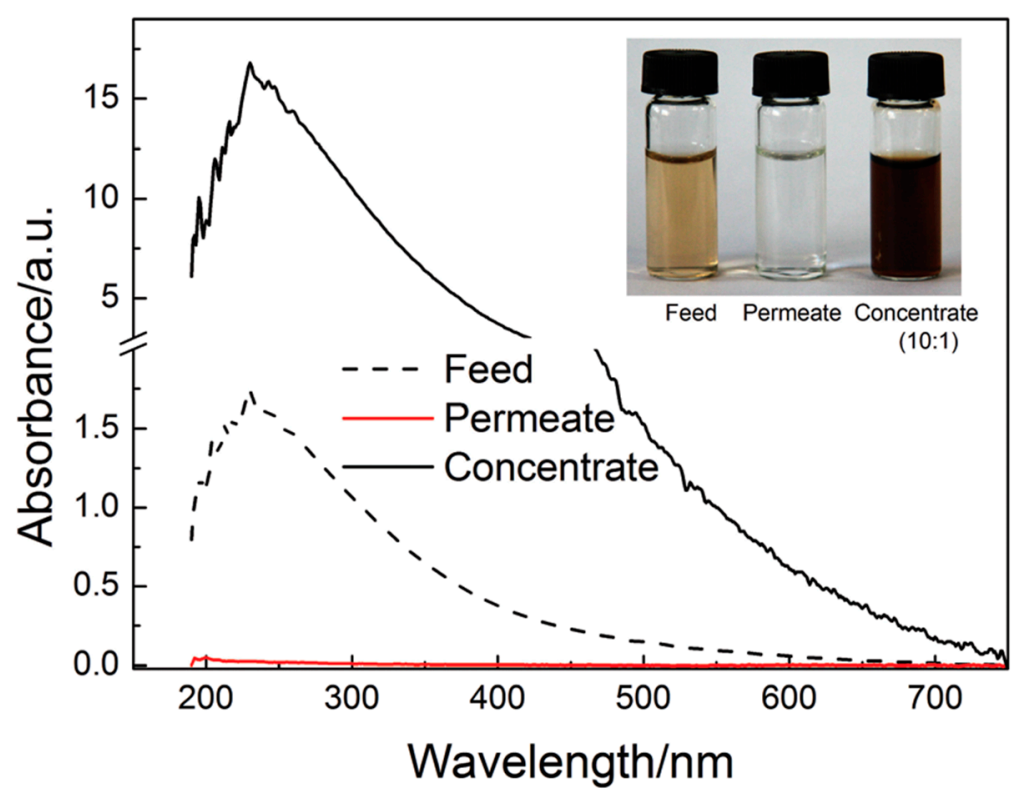

Figure 10. Performance of a reduced graphene oxide (rGO)/MWNT hybrid membrane for removing fulvic acid (initial feed concentration $50 \mathrm{ppm}$ ) from water. Reproduced from Reference [95] with permission from the Royal Society of Chemistry.

The above rGO/MWNT hybrid membrane was also highly effective at retaining Au NPs, bovine serum albumin (BSA), and the organophosphate insecticide phoxim. Retention values $>90 \%$ were obtained for experiments involving one of the above solutes (Figure 11). During these experiments, 
the permeability of water was determined to be between 22 and $30 \mathrm{~L} \cdot \mathrm{m}^{-2} \cdot \mathrm{h}^{-1} \cdot \mathrm{bar}^{-1}$, which was markedly larger than what had been reported for graphene nanofiltration membranes in the literature [96].

The introduction of CNTs into commercial membranes has been shown to alter the selectivity of the latter, without greatly affecting their intrinsic permeability [97,98]. In one such study, the effect of modifying polyacrylonitrile (PAN) membranes with SWNTs, on their ability to recover low molecular weight micropollutants, was investigated [99]. The composite membranes were prepared by a phase inversion method, in which SWNTs were first dispersed in DMF using ultrasonication. PAN was then added to the resulting DMF solution, which was cast onto a glass plate and subsequently immersed in a coagulation bath containing deionised water and isopropanol. After the PAN/SWNT membranes had precipitated, they were stored in deionised water to ensure complete phase separation. It was observed that the structure of the membranes changed significantly, depending on the amount of nanotubes added, with those having the highest CNT contents exhibiting the highest capacity towards micropollutants.

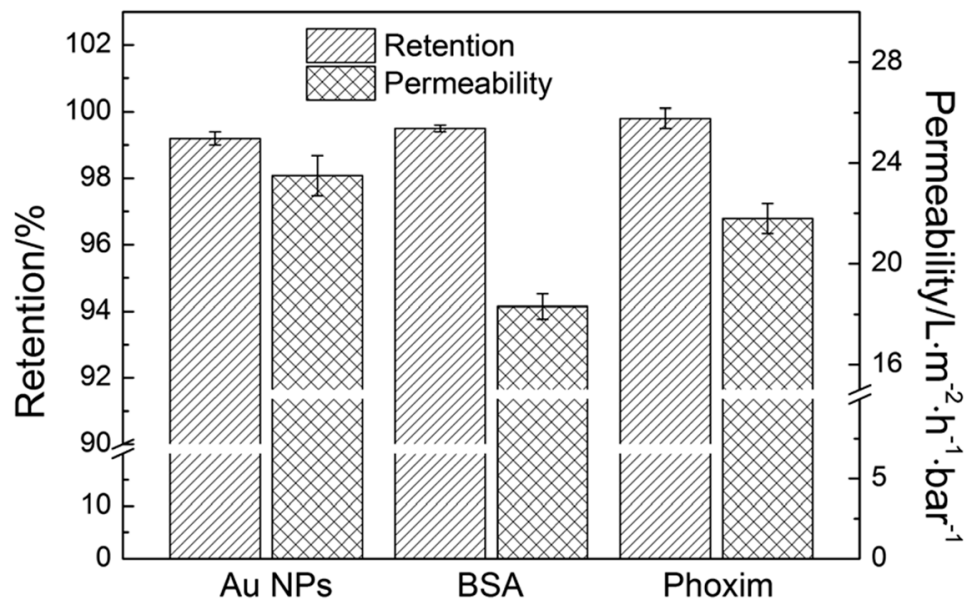

Figure 11. Performance of rGO/MWNT hybrid NF membranes during experiments involving feed solutions containing Au nanoparticles, bovine serum albumin (BSA), or phoxim. Reproduced from Reference [95] with permission from the Royal Society of Chemistry.

Figure 12 illustrates the effect of changing the amount of SWNTs incorporated into these membranes on their ability to remove BPA and 4-nonylphenol (4-NP), as well as their permeate flux. Also included are data for a composite PAN membrane containing $1 \% \mathrm{SWNT}-\mathrm{COOH}$. The permeate flux exhibited by the latter membrane was about $80 \%$ higher than that for an unmodified PAN membrane. Increasing the amount of SWNTs present in the membranes from $0 \%$ to $0.2 \%$, and then $0.5 \%$, resulted in a significant enhancement in the ability to remove both types of micropollutants. Somewhat surprisingly, however, further increasing the amount of SWNTs incorporated to 1.0\% adversely affected recovery levels, but not the permeate flux. Figure 12 also shows that the ability of a composite membrane containing $1.0 \% \mathrm{SWNT}-\mathrm{COOH}$ to recover both micropollutants was greater than for the corresponding materials containing the same amount of SWNTs [99].

Pharmaceuticals and personal care products are widely used in modern society, and are persistently released into aquatic environments. As a consequence, there is an urgent need for energy-efficient technologies that can be used to control the levels of these pollutants. One recent study examined the effectiveness of nanocomposite membranes consisting of a layer of SWNTs or MWNTs deposited on PVDF, for the removal of triclosan, acetaminophen, and ibuprofen from aqueous solutions [100]. The membranes were prepared by first dispersing SWNTs, MWNTs, or carboxylated MWNTs in $10 \mathrm{~mL}$ of ultrapure water using ultrasonication, and then filtering the resulting suspensions slowly through a flat piece of PVDF contained in a glass syringe. The extent of removal of the above 
model pollutants ranged from $10 \%$ to $95 \%$, and was found to increase with the number of aromatic rings in their structures. In addition, the greater specific surface area of membranes containing SWNTs resulted in higher recovery levels.

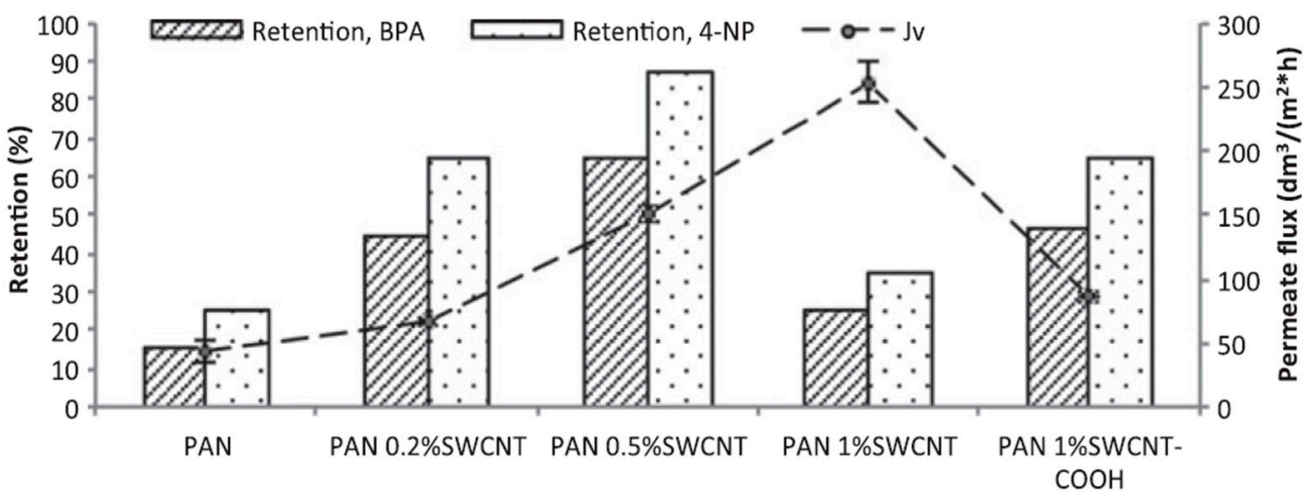

Figure 12. Effect of SWNT loading on wastewater flux (at 0.5 bar) and the removal of bisphenol A (BPA) and 4-nonylphenol (4-NP) by composite polyacrylonitrile (PAN)/SWNT membranes. Reproduced with permission from Reference [99]. Copyright Taylor and Francis, 2016.

In order to determine the adsorption capacities of the different CNT membranes towards mixtures of triclosan (TCS) and ibuprofen (IBU), the amounts of these two pollutants that had adsorbed onto the membranes was measured. The results obtained showed that the adsorption of triclosan by an unmodified PVDF membrane reached saturation within $40 \mathrm{~min}$. In contrast, the amount of triclosan adsorbed by composite SWNT/PVDF and MWNT/PVDF membranes increased in an almost linear fashion for up to $200 \mathrm{~min}$, regardless of whether or not Suwannee River fulvic acid (SRFA) was also present (Figure 13A). These results indicated that the adsorption of triclosan had not reached saturation under the conditions used. Similar trends were observed during experiments in which the adsorption of ibuprofen by the composite CNT membranes was examined (Figure 13B).

(A)

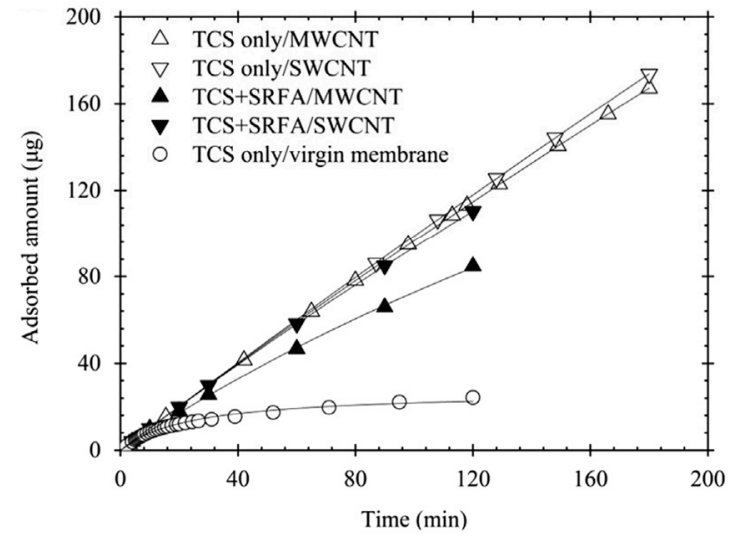

(B)

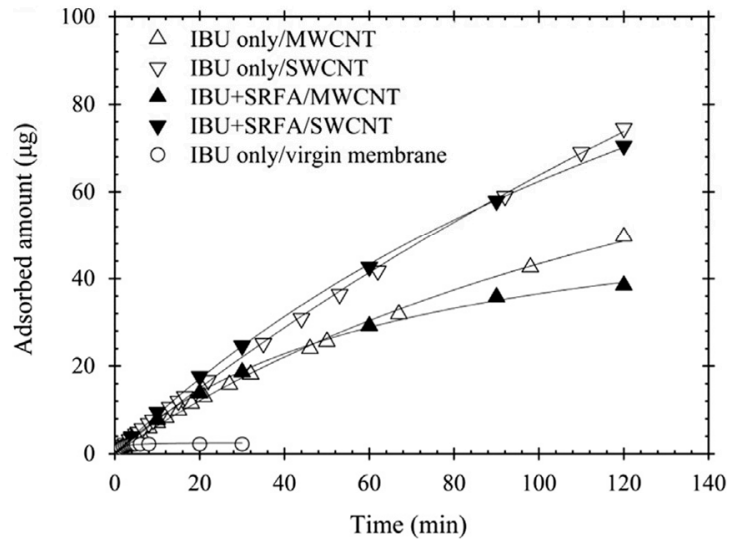

Figure 13. Effect of time on the adsorption of: (A) triclosan; and (B) ibuprofen by SWNT/PVDF and MWNT/PVDF composite membranes, both in the absence and presence of Suwannee River fulvic acid (SRFA). Reprinted with permission from Reference [100]. Copyright Elsevier, 2015.

The ability of CNT membranes such as those described above to remove different organic pollutants is not surprising, given the potential for raw CNTs to achieve this objective through adsorption $[49,101]$. In addition, we were able to obtain evidence via mass balance calculations, for adsorption playing a significant role in the ability of a variety of different types of BPs to remove 
bisphenol A from aqueous solutions [102]. The BPs used in this investigation were prepared from dispersions containing either unsubstituted MWNTs, or functionalized MWNTs (MWNT-NH ${ }_{2}$ and MWNT-COOH), as well as a dispersant molecule (Triton X-100 (Trix) or phthalocyaninetetrasulfonic acid (PTS)) that was retained in the structure of the membrane. Of the BPs examined, MWNT/PTS proved to be much less effective at removing bisphenol A. Similarly, MWNT/PTS membranes were found to be less effective than MWNT/Trix BPs for removing a mixture of twelve different trace organic contaminants. This was attributed to the significantly lower surface area of the former material, which would be expected to limit its effectiveness at removing contaminants by an adsorptive mechanism. In a subsequent study, we showed that BPs prepared from dispersions containing SWNTs and biopolymer dispersants could also remove, to varying extents, the same mixture of twelve organic contaminants [103]. In addition, an experiment designed to explore the ability of the BPs to reject a mixture of $\mathrm{NaCl}$ and $\mathrm{MgSO}_{4}$ was undertaken, in order to examine their potential for nanofiltration and desalination. The extent of rejection of $\mathrm{MgSO}_{4}$ by the two BPs investigated was found to be higher than that for $\mathrm{NaCl}$. This was most likely due to the greater degree of attraction between the divalent ions in $\mathrm{MgSO}_{4}$, and polar or charged functional groups present on the surface of the BPs owing to the retention of biopolymer molecules within their structure.

\subsection{Desalination Applications}

Several groups have demonstrated that it is possible to desalinate water samples with a relatively low salinity (< 5000 $\mathrm{mg} \cdot \mathrm{L}^{-1}$ of $\mathrm{NaCl}$ ), by using electrodes consisting of electrochemically activity composite films containing both CNTs and carbon nanofibers, and capacitive de-ionisation apparatus [104-106]. This application took advantage of the electrical conductivity and high porosity of composite films containing both CNTs and CNFs. The capacitive de-ionisation apparatus used consisted of two electrodes that formed a capacitor, across which a voltage was applied to adsorb ions of opposite polarity from a stream of salty water. When the applied potential was reversed, the salt was then released in the form of a concentrated brine solution.

In an alternative approach to desalting aqueous solutions, Dumee et al. used a self-supporting BP in conjunction with a direct contact membrane distillation apparatus [107]. These researchers prepared their BPs from dispersions of MWNTs in isopropanol, and were able to use these membranes to reject $99 \%$ of the salt present in water samples. The highly hydrophobic BPs were used to separate a feed solution consisting of hot sea water or brackish water, from a permeate comprised of cold fresh water. While liquid could not cross the membrane, water vapour was able to pass through the pores from the hot feed solution to the cold permeate, driven by the difference in partial vapour pressure. The water vapour then condensed on the permeate side, creating fresh water. The inherent hydrophobicity of CNTs, combined with the high porosity of the BP, made the latter ideal for this application. This was reflected in the water vapour permeabilities up to $3.3 \times 10^{-12} \mathrm{~kg} \cdot \mathrm{m}^{-1} \cdot \mathrm{s}^{-1} \cdot \mathrm{Pa}^{-1}$ that were observed using a small scale rig [107]. In a subsequent study, the same authors studied the desalination potential of poly(tetrafluoroethylene) (PTFE) coated BPs, which displayed an enhanced hydrophobicity and improved mechanical stability [108]. These materials also exhibited improved lifespans, as well as excellent water permeability and salt rejection properties. For example, a $99 \%$ rejection of the salt was observed with feed solutions containing high $\mathrm{NaCl}$ concentrations $\left(35 \mathrm{~g} \cdot \mathrm{L}^{-1}\right)$.

Recently, a novel class of hybrid nanofiltration membranes were fabricated via in-situ ionic cross-linking between sodium alginate, polyethyleneimine, and MWNT-COOH [109]. It was shown that the permeability of these hybrid membranes towards water doubled from 13.4 to $27.0 \mathrm{~L} \mathrm{~m}^{-2} \cdot \mathrm{h}^{-1}$, when the mass ratio of MWNTs to sodium alginate was increased from 0.00 to 0.05 . In addition, they showed higher levels of $\mathrm{MgCl}_{2}$ rejection (93.5\%), and greater $\mathrm{Na}^{+} / \mathrm{Mg}^{2+}$ selectivity, compared to other nanofiltration membranes containing polyelectrolytes.

Graphene is a two-dimensional carbon material that also shows great promise as a membrane nanomaterial [110,111]. Recently, it was shown that graphene membranes composed of stacked graphene oxide (GO), or chemically converted graphene (CCG), possess aligned nanochannel arrays 
that can efficiently separate molecules in the gas or liquid phase [112-115]. Although earlier graphene membranes had been reported to exhibit high water fluxes, their ability to reject pollutants was usually much lower than that of commercial nanofiltration membranes. Recently, however, Han et al. reported the preparation of a graphene nanofiltration membrane consisting of densely stacked CCG layers, which exhibited comparable rejection properties to a commercial nanofiltration membrane in experiments involving both a simple salt $\left(\mathrm{Na}_{2} \mathrm{SO}_{4}\right)$ and organic dyes [96]. One disadvantage, however, was that the graphene membrane exhibited a relatively low degree of permeability towards water $\left(\right.$ flux $\left.=3.3 \mathrm{~L} \cdot \mathrm{m}^{-2} \cdot \mathrm{h}^{-1} \cdot \mathrm{bar}^{-1}\right)$. It was hypothesized that the narrow spaces between the graphene sheets in these membranes were the main cause of their low water flux. To overcome this issue, the same research group later prepared graphene/CNT composite membranes by assembling rGO and MWNTs on a porous substrate. The rationale behind the design of these new membranes was that the reduced graphene oxide would facilitate molecular sieving interactions, while the MWNTs would expand the interlayer space between neighbouring graphene sheets, leading to higher water fluxes [116].

Electron microscopy studies on the above rGO/MWNT membranes revealed that the nanotubes had been inserted into the graphene sheets, without disturbing the morphology of the latter. This was attributed to the flexibility of graphene oxide and excellent compatibility between graphene and CNTs. A transmission electron microscopic examination of the materials indicated that the MWNTs were well dispersed throughout the membranes. Nanofiltration experiments conducted using a dead-end filtration device with the $\mathrm{rGO} / \mathrm{MWNT}$ membranes showed water fluxes up to $11.3 \mathrm{~L} \cdot \mathrm{m}^{-2} \cdot \mathrm{h}^{-1} \cdot \mathrm{bar}^{-1}$, which was more than twice that of neat graphene membranes. In addition, the rGO/MWNT membrane exhibited high levels of dye rejection (>99\% for Direct Yellow and $>96 \%$ Methyl Orange), and a significant ability to reject salt (83.5\% rejection for $\mathrm{Na}_{2} \mathrm{SO}_{4}, 51.4 \%$ rejection for $\left.\mathrm{NaCl}\right)$ [116]. A further advantage exhibited by the rGO/MWNT membranes was a greater antifouling ability, which was attributed to lower levels of roughness and a higher hydrophilicity [116].

\section{Resistance to Fouling}

Recent interest in CNTs also stems from research that showed they improve the antifouling properties of commercial ultrafiltration membranes. For example, in a recent study by Guo et al., the effects of modifying the surface of polyethersulfone (PES) membranes with BPs on their susceptibility to fouling was investigated [117]. Composite membranes were fabricated by filtering a suspension of MWNTs through a commercial PES membrane in a dead-end ultrafiltration unit. The pure water flux of the composite material was significantly greater than that exhibited by a pure PES membrane. It was also shown that the BP layer could trap pollutants present in sewage effluent on the surface of the composite, thereby preventing them from reaching the underlying PES membrane. The ability of the composite membrane to remove humic acid from aqueous solutions was also significantly greater than that of the unmodified PES membrane.

Another recent investigation into the antifouling properties of composite membranes containing CNTs was performed by Bai et al. [118]. The composite membranes examined were prepared using MWNT-COOH or MWNTs that had been covalently functionalised with polyethylene glycol (MWNT-PEG). A PES ultrafiltration membrane was then coated with either raw or functionalised MWNTs, resulting in composite materials that had rougher surfaces than the underlying support material. Investigations into the antifouling properties of the different types of composite materials were conducted using humic acid, BSA, and sodium alginate. In each case, the composite membranes exhibited significantly improved antifouling properties compared to the PES membrane alone [118]. Each of the modified membranes showed significantly higher fluxes than a pure PES membrane after exposure to increasing amounts of humic acid. These results clearly illustrated that a potential application of BPs is to enhance the overall performance of commercial membranes by minimising fouling, thereby reducing running costs and increasing operational lifetimes. 


\section{Enhancing Fouling Performance through Electrical Stimulation}

To date, there have been very few studies which have sought to take advantage of the electrical conductivity of BPs in order to achieve superior outcomes for a filtration process. One such study involved the use of self-supporting and electrochemically active MWNT BP filters for the adsorptive removal and electrochemical oxidation of a number of water-soluble dyes [119]. The first stage of preparation of the BPs involved dispersing MWNTs in DMSO using probe sonication. Vacuum filtration of the resulting dispersions through $5 \mu \mathrm{m}$ PTFE membranes then afforded the self-supporting MWNT BPs. In the absence of an applied electrical potential, the MWNT BP filter completely removed methylene blue and methyl orange from an influent solution, until a monolayer consisting of dye molecules had adsorbed to its surface. In a separate experiment, the application of an electrical potential $(2 \mathrm{~V})$ to an identical BP resulted in oxidation of $>98 \%$ of influent dye molecules after a single pass through the membrane. The efficient removal of dye molecules was attributed to their planar aromatic structures, which promoted adsorption to the anodic MWNT surface. These results highlighted the potential of electrochemically active MWNT BPs for the adsorptive removal and oxidative degradation of aqueous contaminants.

The oxidation of methylene blue has also been achieved through the application of oxidizing electrochemical potentials to polyaniline/MWNT composite membranes [120]. The latter showed a number of favourable attributes for this application, including significant levels of hydrophobicity and electrical conductivity. In addition, the membranes showed improved levels of stability towards the oxidizing conditions required to effect the oxidation of methylene blue. Furthermore, there was little evidence of deterioration apparent when the membranes were subjected to a potential of $3 \mathrm{~V}$ (vs. $\mathrm{Ag} / \mathrm{AgCl}$ ) at neutral $\mathrm{pH}$. Under a variety of conditions, the polyaniline/MWNT composite outperformed an analogous polyvinyl alcohol/MWNT composite material in experiments conducted to test their ability to oxidise methylene blue. In addition, the use of anodic potentials was found to confer a pronounced ability on the polyaniline/MWNT composite to inhibit fouling by BSA, provided chloride ions were present in the reaction medium. This led the authors to conclude that the primary agent responsible for the removal of the protein foulant was chlorine, generated by the electrochemical oxidation of chloride ions.

The above study is just one example of a growing number of investigations that have explored the use of electrochemical methods and the conductivity of CNT membranes, to minimize fouling by organic substances and/or bacteria. The inhibition of microbial attachment was also demonstrated in experiments involving CNT/polyvinyl alcohol composite materials and E. coli [121]. The inhibition of bacterial cell attachment was achieved when the membrane was operated as either an anode or a cathode. It was proposed that hydrogen peroxide, which formed as a result of the application of low electrochemical potentials to the membrane, was responsible for the observed results, as it leads to a reduction in cell membrane permeability, and therefore, the overall health of the bacteria.

Significant reductions in membrane fouling by organic compounds have also been achieved using robust and electrically conductive membranes prepared using MWNT-COOH and cross-linked PVA [122]. The preparation of these membranes used MWNT-COOHs that had been dispersed in aqueous solutions containing dodecylbenzenesulfonic acid (DDBS), using a horn sonicator. The resulting MWNT-COOH dispersion, and a solution of PVA, were then pressure deposited onto a commercial polysulfone (PS-35) ultrafiltration membrane. This resulted in the formation of modified (PVA/MWNT-COOH/PS-35) membranes that were then incorporated into an electrofiltration cell, in order to study the effects of applied potentials on the extent of membrane fouling in the presence of high concentrations $\left(3-5 \mathrm{~g} \cdot \mathrm{L}^{-1}\right)$ of negatively charged alginic acid.

Higher fouling rates were observed for unmodified PS-35 membranes compared to PVA/MWNT-COOH/PS-35 membranes. In addition, the application of an electrical potential of $-3 \mathrm{~V}$ or $-5 \mathrm{~V}$ to modified membranes for $100 \mathrm{~min}$ resulted in much smaller reductions in the operating pressure (33\% and 51\%, respectively), compared to when no voltage was applied (Figure 14). This was 
due to the applied potentials inhibiting fouling, as a result of repulsive electrostatic forces between the negatively charged membrane and alginic acid [122].

The effect of applied potentials on biofilm formation was also examined in a study involving polyamide/MWNT-COOH composite membranes [123]. These exhibited high electrical conductivity $\left(\sim 400 \mathrm{~S} \mathrm{~m}^{-1}\right)$ and good $\mathrm{NaCl}$ rejection properties $(>95 \%)$. The ability of the composite membranes to resist fouling caused by bacteria was then compared to that of the conventional polyamide support material. When the latter was used, a non-reversible decline in water flux was observed in experiments involving a feed solution containing pseudomonas aeruginosa, a model biofouling bacterium. This was attributed to biofilm formation, which could not be reversed by the application of a cross-flow rinse with the feed solution. In contrast, the decrease in flux observed when the polyamide/MWNT-COOH nanocomposite membranes were tested under the same conditions, and with an electrical potential applied to their surface, was only caused by the deposition of bacteria, rather than bacterial attachment. This was shown by experiments in which the flux was restored to its initial levels following a short rinse with the feed solution. The inhibition of biofilm formation on the nanocomposite membranes was shown to be a long-term effect, which did not decrease with membrane use, and was highly reproducible.

Membrane filtration technology provides feasible solutions for removing contaminants, but achieving a high permeability, good selectivity, and antifouling capability still remains a challenge for existing filtration technologies. Recently, Fan et al. applied a new strategy in which membrane filtration was coupled with electrochemistry to enhance the performance of an MWNT/ $\mathrm{Al}_{2} \mathrm{O}_{3}$ composite membrane [124]. The synthesis of the composite membrane was achieved by first dispersing oxidised MWNTs in DMF also containing $0.5 \mathrm{wt} \%$ polyacrylonitrile. The resulting MWNT/PAN dispersion was then vacuum filtered onto a porous $\mathrm{Al}_{2} \mathrm{O}_{3}$ substrate, producing an MWNT/PAN/ $\mathrm{Al}_{2} \mathrm{O}_{3}$ membrane which was pyrolysed at $1000^{\circ} \mathrm{C}$ under an atmosphere of hydrogen. The final membrane exhibited a good pore-size tunability, mechanical stability, and electrical conductivity [124].

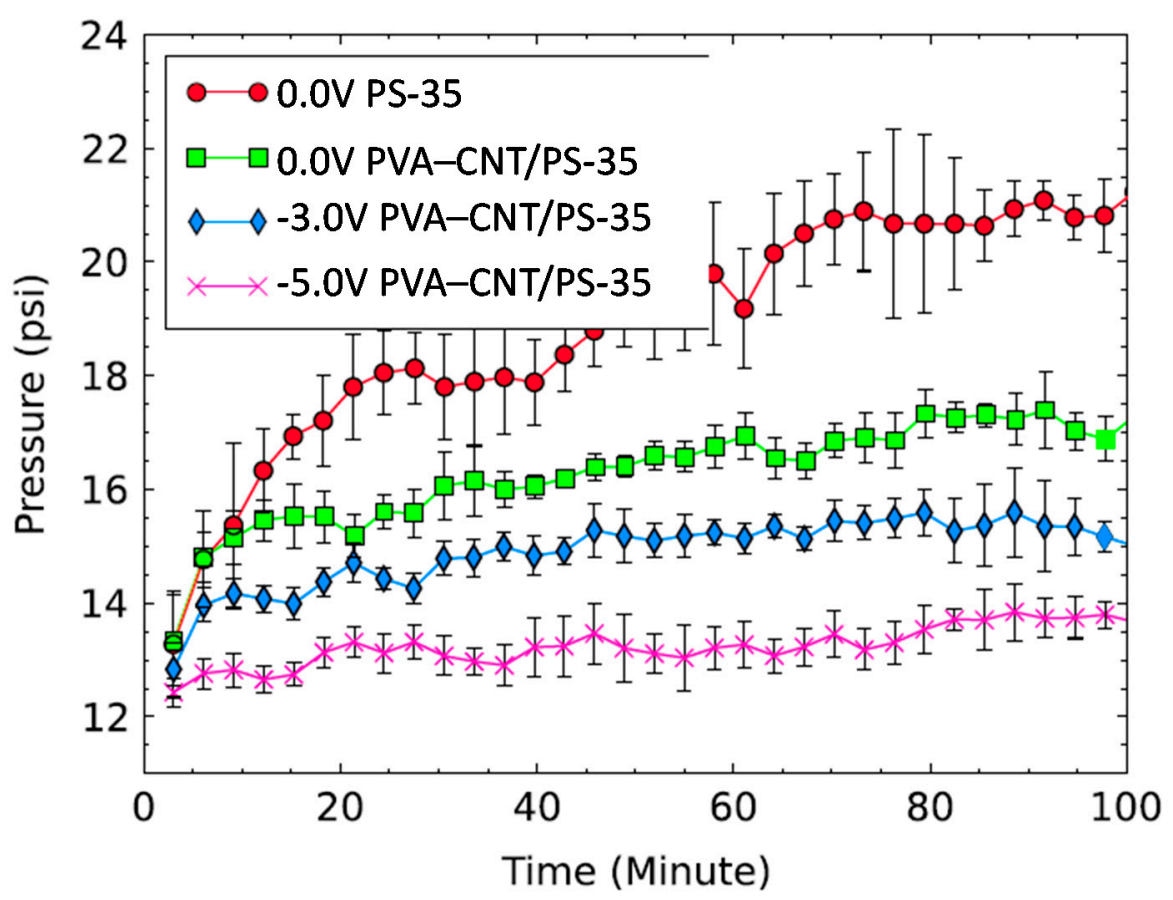

Figure 14. Effect of application of negative potentials to PVA/MWNT-COOH/PS-35 membranes on the extent of fouling caused by a solution consisting of $5 \mathrm{~g} \cdot \mathrm{L}^{-1}$ alginic acid. Reduced levels of fouling led to smaller increases in applied pressure being required to maintain membrane operation. Reproduced with permission from Reference [122]. Copyright Elsevier, 2014. 
In addition, the $\mathrm{MWNT} / \mathrm{PAN} / \mathrm{Al}_{2} \mathrm{O}_{3}$ composite membrane exhibited improved permeate fluxes and the ability to remove contaminants when electrochemical stimuli were applied [124]. Figure 15A shows that the total organic carbon (TOC) removal efficiency exhibited by the $\mathrm{MWNT} / \mathrm{PAN} / \mathrm{Al}_{2} \mathrm{O}_{3}$ membrane in the absence of electrochemical stimulation was just $28.9 \%$. However, this increased to $46.7 \%, 71.3 \%$, and $87.7 \%$, when the membrane was subjected to constant applied potentials of +0.5 , +1.0 , and $+1.5 \mathrm{~V}$, respectively [124].
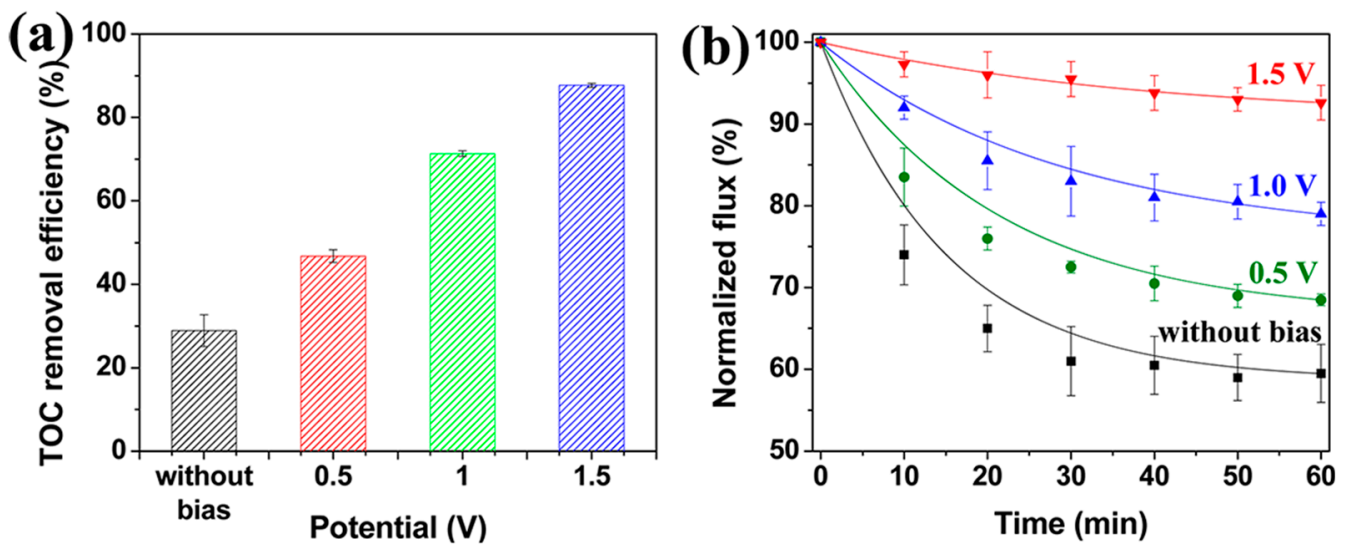

Figure 15. Effect of an applied electrochemical potential on the performance of a MWNT/PAN/ $\mathrm{Al}_{2} \mathrm{O}_{3}$ membrane exposed to humic acid: (a) effect on total organic carbon (TOC) removal efficiency; (b) normalised permeate flux. Reprinted with permission from Reference [124]. Copyright American Chemical Society, 2015.

Figure 15B shows the effects of the above electrochemical stimuli on the permeate flux of the $\mathrm{MWNT} / \mathrm{PAN} / \mathrm{Al}_{2} \mathrm{O}_{3}$ membrane. In the absence of an applied electrochemical potential, the normalised permeate flux of the membrane decreased to $59.5 \%$ after $60 \mathrm{~min}$ of operation, owing to fouling caused by the accumulation of humic acid [124]. This was confirmed by the observation of a layer of organic matter on the membrane surface. In contrast, permeate fluxes of $68.5 \%, 79 \%$, and $92.6 \%$ were observed when applied potentials of $+0.5,+1.0$, and $+1.5 \mathrm{~V}$, respectively, were used [124]. These results showed that the loss of permeability of the MWNT/PAN/ $\mathrm{Al}_{2} \mathrm{O}_{3}$ membrane was mitigated through the use of an electrochemical signal. Consistent with this, the SEM image of the membrane used in the experiment performed using an electrochemical potential of $+1.5 \mathrm{~V}$ showed a much smaller accumulation of humic acid on its surface.

Similar results were obtained by the same research group when electropolarisation was used in conjunction with a conductive MWNT/ceramic composite membrane [125]. The first step towards the preparation of the latter involved dispersing carboxylated MWNTs into a $0.5 \mathrm{wt} \%$ PAN/DMF solution using ultrasonication. The resulting dispersion was then used to coat a hollow fibre substrate with the assistance of vacuum filtration. The resulting materials were heated at $250{ }^{\circ} \mathrm{C}$ for $3 \mathrm{~h}$ in air, and then subjected to pyrolysis at $1000{ }^{\circ} \mathrm{C}$ under a hydrogen atmosphere, to afford the final MWNT/ceramic composite membranes. When an electrical potential was applied, the latter exhibited a permeate flux 8.1 times higher than that observed in the absence of electropolarisation, in experiments involving the filtration of a feed solution containing bacteria. In addition, the permeate flux of the composite membrane was 1.5 times larger when electropolarisation was used to filter an aqueous solution containing natural organic matter. These results demonstrated a high level of performance of the new membrane with respect to mitigating biofouling.

Figure 16 shows the effect of operating time on both the normalised water flux and the ability to remove NOM, of this new type of composite membrane, when used in conjunction with different types of electrical potential. On each occasion, the results obtained were superior to those observed when no electrical stimulation was used [125]. Increases in permeate flux were ascribed to the mitigation 
of fouling of the MWNT/ceramic membrane by organic components, owing to the application of electropolarisation.
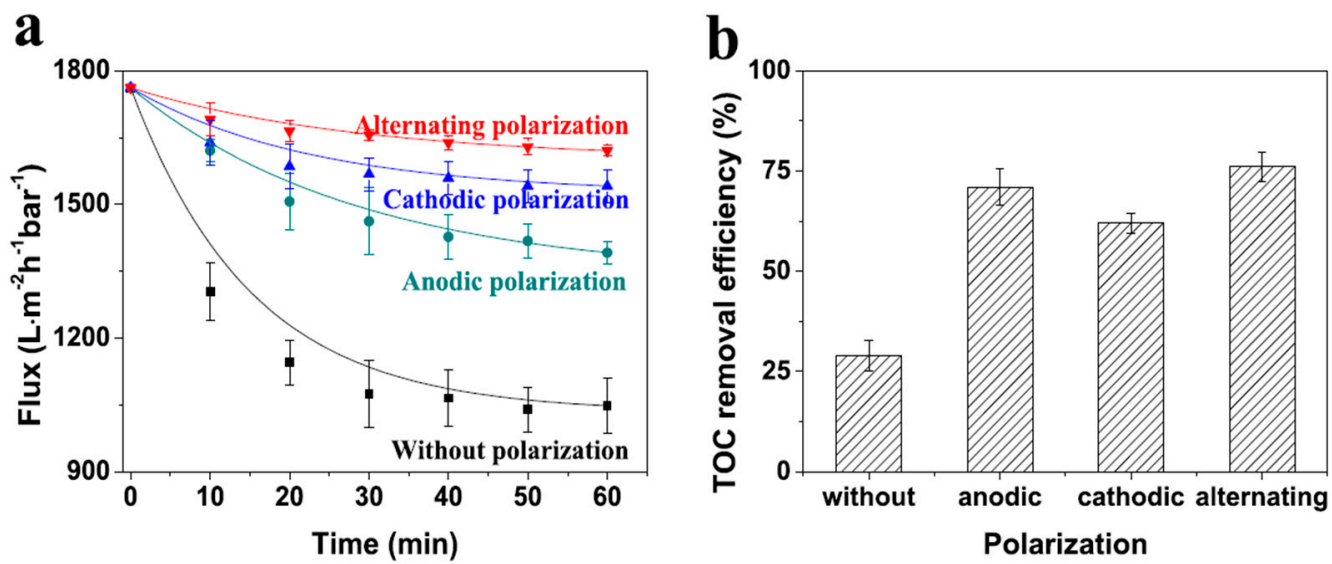

Figure 16. Effect of different types of electrochemical stimulation on the performance of an MWNT/ceramic membrane during filtration experiments performed using solutions containing natural organic matter: (a) Effect on normalised permeate flux of water; (b) Effect on TOC removal efficiency. Reproduced with permission from Reference [125]. Copyright Elsevier, 2015.

Similar promising results were obtained from fouling mitigation experiments performed using the MWNT composite membranes, and aqueous feed solutions that contained both natural organic matter and E. coli [125]. In the absence of electropolarisation, the permeate flux was $846 \mathrm{~L} \cdot \mathrm{m}^{-2} \cdot \mathrm{h}^{-1} \cdot \mathrm{bar}^{-1}$. In contrast, values of 1065,1410 , and $1570 \mathrm{~L} \cdot \mathrm{m}^{-2} \cdot \mathrm{h}^{-1} \cdot \mathrm{bar}^{-1}$ were obtained after $60 \mathrm{~min}$ filtration, when alternating electrical biases of $\pm 0.5, \pm 1.0$, and $\pm 1.5 \mathrm{~V}$, respectively, were used. In addition, the efficiency of natural organic matter removal was enhanced more than three-fold, when the membrane was cycled between $\pm 1.5 \mathrm{~V}$ [125].

The above results demonstrate that electrically conductive composite membranes containing CNTs show potentially useful antifouling properties. Further evidence of this was provided by a recent investigation using a new type of dual-layer MWNT/PVDF membrane [126]. When compared to a pristine PVDF membrane, the MWNT/PVDF dual layer membrane exhibited greater electrical conductivity and a $10 \%$ increase in water permeability [126]. When an electrical potential of $1 \mathrm{~V}$ DC or $2 \mathrm{~V} \mathrm{DC}$ was applied, the MWNT/PVDF membrane maintained a lower trans-membrane pressure than the pristine PVDF membrane in experiments performed with solutions containing sodium alginate, BSA, and humic acid. The lower trans-membrane pressure was attributed to lower levels of fouling, as a result of the applied electric field.

Composite membranes consisting of MWNTs and calcium alginate (CA) also exhibited low levels of fouling, even in the absence of any electrochemical assistance. It had already been shown that CNT doped alginate composites exhibited good mechanical strength, and can be used to remove heavy metal ions, dye molecules, and natural organic matter from wastewater by acting as an adsorbent $[127,128]$. In order to incorporate those characteristics into filtration membranes, Jie et al. prepared MWNT/CA hydrogel membranes, by using $\mathrm{Ca}^{2+}$ to crosslink the CNTs and CA in the presence of polyethylene glycol 400 (PEG400), which served as a pore-forming agent [129]. The strength, antifouling properties, and dye rejection capabilities of the MWNT/CA membranes were investigated. When the feed solution was changed from pure water to a solution containing BSA, the permeate flux reduced only slightly. Furthermore, after repeated operation, the permeate flux remained at ca. $~ 90 \%$ of the value obtained when pure water was used as the feed. These results were obtained without any washing operations being performed between experiments, indicating that the MWNT/CA filtration membrane exhibited excellent protein antifouling properties. In addition, the MWNT/CA composite membrane showed a 
$99 \%$ rejection of Congo Red, indicating that it can be used as a nanofiltration membrane to remove small organic molecules present in wastewater.

The ability of a new type of nanocomposite membrane, consisting of polysulfone (PSf) with embedded MWNTs, to resist fouling by organic molecules was also recently investigated [130]. Before embedding into the polymer matrix, the MWNTs were first treated with $\mathrm{HNO}_{3}$ to introduce carboxylic acid functional groups onto their surface, and to facilitate modification with dodecylamine. The final nanocomposite membranes exhibited a significantly higher permeability and protein fouling resistance than pristine PSf membranes, when used in filtration experiments using solutions containing BSA [130].

\section{Conclusions}

Researchers were first drawn to the potential of CNTs for filtration applications as a result of the tremendous permeability exhibited by aligned membranes, and their exquisite ability to discriminate between small molecules on the basis of differences in size. Their level of performance in these areas is yet to be matched by other classes of CNT membranes such as BPs and CNT composites. However, the latter offer a number of advantages such as a lower cost and greater ease of production, as well as the ability to be produced on a larger scale. As a consequence, researchers are increasingly looking towards these materials for a host of new applications, including the filtration of air samples, removal of bacteria and other pathogens from water supplies, desalination, and the separation of a wide range of organic compounds of environmental concern. Investigations into these applications have shown that CNT composite membranes often show enhanced resistance to biofouling compared to the conventional polymeric or ceramic substrates used in their preparation. In addition, recent work has shown that it is possible to enhance the anti-fouling properties of these materials by taking advantage of their inherent conductivity and using different forms of applied electrochemical stimulation. These results suggest that a very important application of CNTs in the future may be as additives or components of composite membranes whose function is to ensure that they can work with optimum efficiency for extended periods. There is still also a great deal to be learnt about what differences, if any, there are between the filtration characteristics of BPs or composite materials prepared using different classes of CNTs and dispersing agents. In view of these unanswered questions, and the enormous range of support materials that can be used to prepare CNT composites, and the diversity of potential applications, it is certain that research into these materials will continue to expand.

Acknowledgments: Md. Harun-Or Rashid acknowledges the support provided by a University of Wollongong Postgraduate Award.

Conflicts of Interest: The authors declare no conflicts of interest.

\section{References}

1. Iijima, S. Helical microtubules of graphitic carbon. Nature 1991, 354, 56-58. [CrossRef]

2. Calvert, P. Nanotube composites: A recipe for strength. Nature 1999, 399, 210-211. [CrossRef]

3. Spinks, G.M.; Mottaghitalab, V.; Bahrami-Samani, M.; Whitten, P.G.; Wallace, G.G. Carbon-nanotubereinforced polyaniline fibers for high-strength artificial muscles. Adv. Mater. 2006, 18, 637-640. [CrossRef]

4. Kim, S.; Jinschek, J.R.; Chen, H.; Sholl, D.S.; Marand, E. Scalable fabrication of carbon nanotube/polymer nanocomposite membranes for high flux gas transport. Nano Lett. 2007, 7, 2806-2811. [CrossRef] [PubMed]

5. Barone, P.W.; Baik, S.; Heller, D.A.; Strano, M.S. Near-infrared optical sensors based on single-walled carbon nanotubes. Nat. Mater. 2005, 4, 86-92. [CrossRef] [PubMed]

6. Baughman, R.H.; Cui, C.; Zakhidov, A.A.; Iqbal, Z.; Barisci, J.N.; Spinks, G.M.; Wallace, G.G.; Mazzoldi, A.; De Rossi, D.; Rinzler, A.G.; et al. Carbon nanotube actuators. Science 1999, 284, 1340-1344. [CrossRef] [PubMed]

7. Holt, J.K.; Park, H.G.; Wang, Y.; Stadermann, M.; Artyukhin, A.B.; Grigoropoulos, C.P.; Noy, A.; Bakajin, O. Fast mass transport through sub-2-nanometer carbon nanotubes. Science 2006, 312, 1034-1037. [CrossRef] [PubMed] 
8. Kar, S.; Bindal, R.C.; Tewari, P.K. Carbon nanotube membranes for desalination and water purification: Challenges and opportunities. Nano Today 2012, 7, 385-389. [CrossRef]

9. Chen, H.; Sholl, D.S. Predictions of selectivity and flux for $\mathrm{CH}_{4} / \mathrm{H}_{2}$ separations using single walled carbon nanotubes as membranes. J. Membr. Sci. 2006, 269, 152-160. [CrossRef]

10. Skoulidas, A.I.; Ackerman, D.M.; Johnson, J.K.; Sholl, D.S. Rapid transport of gases in carbon nanotubes. Phys. Rev. Lett. 2002, 89, 185901. [CrossRef] [PubMed]

11. Majumder, M.; Chopra, N.; Andrews, R.; Hinds, B.J. Nanoscale hydrodynamics: Enhanced flow in carbon nanotubes. Nature 2005, 438, 44. [CrossRef] [PubMed]

12. Joseph, S.; Aluru, N.R. Why are carbon nanotubes fast transporters of water? Nano Lett. 2008, 8, 452-458. [CrossRef] [PubMed]

13. Falk, K.; Sedlmeier, F.; Joly, L.; Netz, R.R.; Bocquet, L. Molecular origin of fast water transport in carbon nanotube membranes: Superlubricity versus curvature dependent friction. Nano Lett. 2010, 10, 4067-4073. [CrossRef] [PubMed]

14. Whitby, M.; Quirke, N. Fluid flow in carbon nanotubes and nanopipes. Nat. Nano. 2007, 2, 87-94. [CrossRef] [PubMed]

15. Mann, D.J.; Halls, M.D. Water alignment and proton conduction inside carbon nanotubes. Phys. Rev. Lett. 2003, 90, 195503. [CrossRef] [PubMed]

16. Brady-Estévez, A.S.; Kang, S.; Elimelech, M. A single-walled-carbon-nanotube filter for removal of viral and bacterial pathogens. Small 2008, 4, 481-484. [CrossRef] [PubMed]

17. Prasek, J.; Drbohlavova, J.; Chomoucka, J.; Hubalek, J.; Jasek, O.; Adam, V.; Kizek, R. Methods for carbon nanotubes synthesis-review. J. Mater. Chem. A 2011, 21, 15872-15884. [CrossRef]

18. Nikolaev, P.; Bronikowski, M.J.; Bradley, R.K.; Rohmund, F.; Colbert, D.T.; Smith, K.A.; Smalley, R.E. Gas-phase catalytic growth of single-walled carbon nanotubes from carbon monoxide. Chem. Phys. Lett. 1999, 313, 91-97. [CrossRef]

19. Bronikowski, M.J.; Willis, P.A.; Colbert, D.T.; Smith, K.A.; Smalley, R.E. Gas-phase production of carbon single-walled nanotubes from carbon monoxide via the hipco process: A parametric study. Vac. Sci. Technol. A 2001, 19, 1800-1805. [CrossRef]

20. Tasis, D.; Tagmatarchis, N.; Bianco, A.; Prato, M. Chemistry of carbon nanotubes. Chem. Rev. 2006, 106, 1105-1136. [CrossRef] [PubMed]

21. Ma, P.C.; Kim, J.-K.; Tang, B.Z. Functionalization of carbon nanotubes using a silane coupling agent. Carbon 2006, 44, 3232-3238. [CrossRef]

22. Ma, P.-C.; Siddiqui, N.A.; Marom, G.; Kim, J.-K. Dispersion and functionalization of carbon nanotubes for polymer-based nanocomposites: A review. Compos. Part A Appl. Sci. Manuf. 2010, 41, 1345-1367. [CrossRef]

23. Star, A.; Stoddart, J.F.; Steuerman, D.; Diehl, M.; Boukai, A.; Wong, E.W.; Yang, X.; Chung, S.-W.; Choi, H.; Heath, J.R. Preparation and properties of polymer-wrapped single-walled carbon nanotubes. Angew. Chem. Int. Ed. 2001, 40, 1721-1725. [CrossRef]

24. Hill, D.E.; Lin, Y.; Rao, A.M.; Allard, L.F.; Sun, Y.-P. Functionalization of carbon nanotubes with polystyrene. Macromolecules 2002, 35, 9466-9471. [CrossRef]

25. Nepal, D.; Geckeler, K.E. Proteins and carbon nanotubes: Close encounter in water. Small 2007, 3, $1259-1265$. [CrossRef] [PubMed]

26. Nepal, D.; Geckeler, K.E. Ph-sensitive dispersion and debundling of single-walled carbon nanotubes: Lysozyme as a tool. Small 2006, 2, 406-412. [CrossRef] [PubMed]

27. Karajanagi, S.S.; Yang, H.; Asuri, P.; Sellitto, E.; Dordick, J.S.; Kane, R.S. Protein-assisted solubilization of single-walled carbon nanotubes. Langmuir 2006, 22, 1392-1395. [CrossRef] [PubMed]

28. Gorityala, B.K.; Ma, J.; Wang, X.; Chen, P.; Liu, X.-W. Carbohydrate functionalized carbon nanotubes and their applications. Chem. Soc. Rev. 2010, 39, 2925-2934. [CrossRef] [PubMed]

29. Yang, H.; Wang, S.C.; Mercier, P.; Akins, D.L. Diameter-selective dispersion of single-walled carbon nanotubes using a water-soluble, biocompatible polymer. Chem. Commun. 2006, 13, 1425-1427. [CrossRef] [PubMed]

30. Peng, F.; Pan, F.; Sun, H.; Lu, L.; Jiang, Z. Novel nanocomposite pervaporation membranes composed of poly(vinyl alcohol) and chitosan-wrapped carbon nanotube. J. Membr. Sci. 2007, 300, 13-19. [CrossRef]

31. Panhuis, M.I.H.; Heurtematte, A.; Small, W.R.; Paunov, V.N. Inkjet printed water sensitive transparent films from natural gum-carbon nanotube composites. Soft Matter 2007, 3, 840-843. [CrossRef] 
32. Geng, Y.; Liu, M.Y.; Li, J.; Shi, X.M.; Kim, J.K. Effects of surfactant treatment on mechanical and electrical properties of cnt/epoxy nanocomposites. Compos. Part A Appl. Sci. Manuf. 2008, 39, 1876-1883. [CrossRef]

33. Yu, J.; Grossiord, N.; Koning, C.E.; Loos, J. Controlling the dispersion of multi-wall carbon nanotubes in aqueous surfactant solution. Carbon 2007, 45, 618-623. [CrossRef]

34. Kim, T.H.; Doe, C.; Kline, S.R.; Choi, S.M. Water-redispersible isolated single-walled carbon nanotubes fabricated by in situ polymerization of micelles. Adv. Mater. 2007, 19, 929-933. [CrossRef]

35. O'Connell, M.J.; Bachilo, S.M.; Huffman, C.B.; Moore, V.C.; Strano, M.S.; Haroz, E.H.; Rialon, K.L.; Boul, P.J.; Noon, W.H.; Kittrell, C.; et al. Band gap fluorescence from individual single-walled carbon nanotubes. Science 2002, 297, 593-596. [CrossRef] [PubMed]

36. Moore, V.C.; Strano, M.S.; Haroz, E.H.; Hauge, R.H.; Smalley, R.E.; Schmidt, J.; Talmon, Y. Individually suspended single-walled carbon nanotubes in various surfactants. Nano Lett. 2003, 3, 1379-1382. [CrossRef]

37. Hinds, B.J.; Chopra, N.; Rantell, T.; Andrews, R.; Gavalas, V.; Bachas, L.G. Aligned multiwalled carbon nanotube membranes. Science 2004, 303, 62-65. [CrossRef] [PubMed]

38. Elimelech, M.; Phillip, W.A. The future of seawater desalination: Energy, technology, and the environment. Science 2011, 333, 712-717. [CrossRef] [PubMed]

39. Majumder, M.; Chopra, N.; Hinds, B.J. Effect of tip functionalization on transport through vertically oriented carbon nanotube membranes. J. Am. Chem. Soc. 2005, 127, 9062-9070. [CrossRef] [PubMed]

40. Majumder, M.; Keis, K.; Zhan, X.; Meadows, C.; Cole, J.; Hinds, B.J. Enhanced electrostatic modulation of ionic diffusion through carbon nanotube membranes by diazonium grafting chemistry. J. Membr. Sci. 2008, 316, 89-96. [CrossRef] [PubMed]

41. Lee, B.; Baek, Y.; Lee, M.; Jeong, D.H.; Lee, H.H.; Yoon, J.; Kim, Y.H. A carbon nanotube wall membrane for water treatment. Nat. Commun. 2015, 6, 7109. [CrossRef] [PubMed]

42. Majumder, M.; Stinchcomb, A.; Hinds, B.J. Towards mimicking natural protein channels with aligned carbon nanotube membranes for active drug delivery. Life Sci. 2010, 86, 563-568. [CrossRef] [PubMed]

43. López-Lorente, A.I.; Simonet, B.M.; Valcárcel, M. The potential of carbon nanotube membranes for analytical separations. Anal. Chem. 2010, 82, 5399-5407. [CrossRef] [PubMed]

44. Vermisoglou, E.C.; Pilatos, G.; Romanos, G.E.; Karanikolos, G.N.; Boukos, N.; Mertis, K.; Kakizis, N.; Kanellopoulos, N.K. Synthesis and characterisation of carbon nanotube modified anodised alumina membranes. Microporous Mesoporous Mater. 2008, 110, 25-36. [CrossRef]

45. Srivastava, A.; Srivastava, O.N.; Talapatra, S.; Vajtai, R.; Ajayan, P.M. Carbon nanotube filters. Nat. Mater. 2004, 3, 610-614. [CrossRef] [PubMed]

46. Baek, Y.; Kim, C.; Seo, D.K.; Kim, T.; Lee, J.S.; Kim, Y.H.; Ahn, K.H.; Bae, S.S.; Lee, S.C.; Lim, J.; et al. High performance and antifouling vertically aligned carbon nanotube membrane for water purification. J. Membr. Sci. 2014, 460, 171-177. [CrossRef]

47. Li, S.; Liao, G.; Liu, Z.; Pan, Y.; Wu, Q.; Weng, Y.; Zhang, X.; Yang, Z.; Tsui, O.K.C. Enhanced water flux in vertically aligned carbon nanotube arrays and polyethersulfone composite membranes. J. Mater. Chem. A 2014, 2, 12171-12176. [CrossRef]

48. Goh, K.; Karahan, H.E.; Wei, L.; Bae, T.-H.; Fane, A.G.; Wang, R.; Chen, Y. Carbon nanomaterials for advancing separation membranes: A strategic perspective. Carbon 2016, 109, 694-710. [CrossRef]

49. Mauter, M.S.; Elimelech, M. Environmental applications of carbon-based nanomaterials. Environ. Sci. Technol. 2008, 42, 5843-5859. [CrossRef] [PubMed]

50. Goh, P.S.; Ismail, A.F.; Ng, B.C. Carbon nanotubes for desalination: Performance evaluation and current hurdles. Desalination 2013, 308, 2-14. [CrossRef]

51. Das, R.; Abd Hamid, S.B.; Ali, M.E.; Ismail, A.F.; Annuar, M.S.M.; Ramakrishna, S. Multifunctional carbon nanotubes in water treatment: The present, past and future. Desalination 2014, 354, 160-179. [CrossRef]

52. Kim, S.; Fornasiero, F.; Park, H.G.; In, J.B.; Meshot, E.; Giraldo, G.; Stadermann, M.; Fireman, M.; Shan, J.; Grigoropoulos, C.P.; et al. Fabrication of flexible, aligned carbon nanotube/polymer composite membranes by in-situ polymerization. J. Membr. Sci. 2014, 460, 91-98. [CrossRef]

53. Park, S.-M.; Jung, J.; Lee, S.; Baek, Y.; Yoon, J.; Seo, D.K.; Kim, Y.H. Fouling and rejection behavior of carbon nanotube membranes. Desalination 2014, 343, 180-186. [CrossRef]

54. Kim, Y.A.; Muramatsu, H.; Hayashi, T.; Endo, M.; Terrones, M.; Dresselhaus, M.S. Fabrication of high-purity, double-walled carbon nanotube buckypaper. Chem. Vap. Depos. 2006, 12, 327-330. [CrossRef] 
55. Endo, M.; Muramatsu, H.; Hayashi, T.; Kim, Y.A.; Terrones, M.; Dresselhaus, M.S. Nanotechnology: 'buckypaper' from coaxial nanotubes. Nature 2005, 433, 476. [CrossRef] [PubMed]

56. Špitalský, Z.; Aggelopoulos, C.; Tsoukleri, G.; Tsakiroglou, C.; Parthenios, J.; Georga, S.; Krontiras, C.; Tasis, D.; Papagelis, K.; Galiotis, C. The effect of oxidation treatment on the properties of multi-walled carbon nanotube thin films. Mater. Sci. Eng. B 2009, 165, 135-138. [CrossRef]

57. Dharap, P.; Li, Z.; Nagarajaiah, S.; Barrera, E.V. Nanotube film based on single-wall carbon nanotubes for strain sensing. Nanotechnology 2004, 15, 379-382. [CrossRef]

58. Prokudina, N.A.; Shishchenko, E.R.; Joo, O.-S.; Hyung, K.-H.; Han, S.-H. A carbon nanotube film as a radio frequency filter. Carbon 2005, 43, 1815-1819. [CrossRef]

59. Knapp, W.; Schleussner, D. Carbon buckypaper field emission investigations. Vacuum 2002, 69, $333-338$. [CrossRef]

60. Vohrer, U.; Kolaric, I.; Haque, M.H.; Roth, S.; Detlaff-Weglikowska, U. Carbon nanotube sheets for the use as artificial muscles. Carbon 2004, 42, 1159-1164. [CrossRef]

61. Frizzell, C.J.; in het Panhuis, M.; Coutinho, D.H.; Balkus, K.J.; Minett, A.I.; Blau, W.J.; Coleman, J.N. Reinforcement of macroscopic carbon nanotube structures by polymer intercalation: The role of polymer molecular weight and chain conformation. Phys. Rev. B 2005, 72, 245420. [CrossRef]

62. Tanaka, T. Filtration characteristics of carbon nanotubes and preparation of buckypapers. Desalin. Water Treat. 2010, 17, 193-198. [CrossRef]

63. Whitby, R.L.D.; Fukuda, T.; Maekawa, T.; James, S.L.; Mikhalovsky, S.V. Geometric control and tuneable pore size distribution of buckypaper and buckydiscs. Carbon 2008, 46, 949-956. [CrossRef]

64. Coleman, J.N.; Blau, W.J.; Dalton, A.B.; Muñoz, E.; Collins, S.; Kim, B.G.; Razal, J.; Selvidge, M.; Vieiro, G.; Baughman, R.H. Improving the mechanical properties of single-walled carbon nanotube sheets by intercalation of polymeric adhesives. Appl. Phys. Lett. 2003, 82, 1682-1684. [CrossRef]

65. Boge, J.; Sweetman, L.J.; in het Panhuis, M.; Ralph, S.F. The effect of preparation conditions and biopolymer dispersants on the properties of swnt buckypapers. J. Mater. Chem. A 2009, 19, 9131-9140. [CrossRef]

66. Ema, M.; Gamo, M.; Honda, K. A review of toxicity studies of single-walled carbon nanotubes in laboratory animals. Regul. Toxicol. Pharmacol. 2016, 74, 42-63. [CrossRef] [PubMed]

67. Magrez, A.; Kasas, S.; Salicio, V.; Pasquier, N.; Seo, J.W.; Celio, M.; Catsicas, S.; Schwaller, B.; Forró, L. Cellular toxicity of carbon-based nanomaterials. Nano Lett. 2006, 6, 1121-1125. [CrossRef] [PubMed]

68. Manna, S.K.; Sarkar, S.; Barr, J.; Wise, K.; Barrera, E.V.; Jejelowo, O.; Rice-Ficht, A.C.; Ramesh, G.T. Single-walled carbon nanotube induces oxidative stress and activates nuclear transcription factor- $\mathrm{kb}$ in human keratinocytes. Nano Lett. 2005, 5, 1676-1684. [CrossRef] [PubMed]

69. Pulskamp, K.; Diabate, S.; Krug, H.F. Carbon nanotubes show no sign of acute toxicity but induce intracellular reactive oxygen species in dependence on contaminants. Toxicol. Lett. 2007, 168, 58-74. [CrossRef] [PubMed]

70. Rodriguez-Yanez, Y.; Munoz, B.; Albores, A. Mechanisms of toxicity by carbon nanotubes. Toxicol. Mech. Methods 2013, 23, 178-195. [CrossRef] [PubMed]

71. Dong, J.; Ma, Q. Advances in mechanisms and signaling pathways of carbon nanotube toxicity. Nanotoxicology 2015, 9, 658-676. [CrossRef] [PubMed]

72. Ong, L.-C.; Chung, F.F.-L.; Tan, Y.-F.; Leong, C.-O. Toxicity of single-walled carbon nanotubes. Arch. Toxicol. 2016, 90, 103-118. [CrossRef] [PubMed]

73. Viswanathan, G.; Kane, D.B.; Lipowicz, P.J. High efficiency fine particulate filtration using carbon nanotube coatings. Adv. Mater. 2004, 16, 2045-2049. [CrossRef]

74. Zhao, Y.; Zhong, Z.; Low, Z.-X.; Yao, Z. A multifunctional multi-walled carbon nanotubes/ceramic membrane composite filter for air purification. RSC Adv. 2015, 5, 91951-91959. [CrossRef]

75. Nasibulin, A.G.; Kaskela, A.; Mustonen, K.; Anisimov, A.S.; Ruiz, V.; Kivistö, S.; Rackauskas, S.; Timmermans, M.Y.; Pudas, M.; Aitchison, B.; et al. Multifunctional free-standing single-walled carbon nanotube films. ACS Nano 2011, 5, 3214-3221. [CrossRef] [PubMed]

76. Brady-Estévez, A.S.; Schnoor, M.H.; Kang, S.; Elimelech, M. Swnt-mwnt hybrid filter attains high viral removal and bacterial inactivation. Langmuir 2010, 26, 19153-19158. [CrossRef] [PubMed]

77. Kang, S.; Pinault, M.; Pfefferle, L.D.; Elimelech, M. Single-walled carbon nanotubes exhibit strong antimicrobial activity. Langmuir 2007, 23, 8670-8673. [CrossRef] [PubMed]

78. Kang, S.; Herzberg, M.; Rodrigues, D.F.; Elimelech, M. Antibacterial effects of carbon nanotubes: Size does matter! Langmuir 2008, 24, 6409-6413. [CrossRef] [PubMed] 
79. Sweetman, L.J.; Nghiem, L.; Chironi, I.; Triani, G.; In Het Panhuis, M.; Ralph, S.F. Synthesis, properties and water permeability of swnt buckypapers. J. Mater. Chem. A 2012, 22, 13800-13810. [CrossRef]

80. Sweetman, L.J.; Alcock, L.J.; McArthur, J.D.; Stewart, E.M.; Triani, G.; Ralph, S.F. Bacterial filtration using carbon nanotube/antibiotic buckypaper membranes. J. Nanomater. 2013, 2013, 23. [CrossRef]

81. Xiu, Z.-M.; Zhang, Q.-B.; Puppala, H.L.; Colvin, V.L.; Alvarez, P.J.J. Negligible particle-specific antibacterial activity of silver nanoparticles. Nano Lett. 2012, 12, 4271-4275. [CrossRef] [PubMed]

82. Kim, E.-S.; Hwang, G.; Gamal El-Din, M.; Liu, Y. Development of nanosilver and multi-walled carbon nanotubes thin-film nanocomposite membrane for enhanced water treatment. J. Membr. Sci. 2012, 394, 37-48. [CrossRef]

83. Gliga, A.R.; Skoglund, S.; Odnevall Wallinder, I.; Fadeel, B.; Karlsson, H.L. Size-dependent cytotoxicity of silver nanoparticles in human lung cells: The role of cellular uptake, agglomeration and ag release. Part. Fibre Toxicol. 2014, 11, 11. [CrossRef] [PubMed]

84. Ihsanullah; Laoui, T.; Al-Amer, A.M.; Khalil, A.B.; Abbas, A.; Khraisheh, M.; Atieh, M.A. Novel anti-microbial membrane for desalination pretreatment: A silver nanoparticle-doped carbon nanotube membrane. Desalination 2015, 376, 82-93.

85. Roy, S.; Jain, V.; Bajpai, R.; Ghosh, P.; Pente, A.S.; Singh, B.P.; Misra, D.S. Formation of carbon nanotube bucky paper and feasibility study for filtration at the nano and molecular scale. J. Phys. Chem. C 2012, 116, 19025-19031. [CrossRef]

86. Yang, X.S.; Lee, J.; Yuan, L.X.; Chae, S.R.; Peterson, V.K.; Minett, A.I.; Yin, Y.B.; Harris, A.T. Removal of natural organic matter in water using functionalised carbon nanotube buckypaper. Carbon 2013, 59, 160-166. [CrossRef]

87. Choi, J.-H.; Jegal, J.; Kim, W.-N.; Choi, H.-S. Incorporation of multiwalled carbon nanotubes into poly(vinyl alcohol) membranes for use in the pervaporation of water/ethanol mixtures. J. Appl. Polym. Sci. 2009, 111, 2186-2193. [CrossRef]

88. Touchal, S.; Roizard, D.; Perrin, L. Pervaporation properties of polypyrrolidinone-based membranes for etoh/etbe mixtures separation. J. Appl. Polym. Sci. 2006, 99, 3622-3630. [CrossRef]

89. Zereshki, S.; Figoli, A.; Madaeni, S.S.; Galiano, F.; Drioli, E. Pervaporation separation of ethanol/etbe mixture using poly(lactic acid)/poly(vinyl pyrrolidone) blend membranes. J. Membr. Sci. 2011, 373, 29-35. [CrossRef]

90. Yee, K.F.; Ong, Y.T.; Mohamed, A.R.; Tan, S.H. Novel mwcnt-buckypaper/polyvinyl alcohol asymmetric membrane for dehydration of etherification reaction mixture: Fabrication, characterisation and application. J. Membr. Sci. 2014, 453, 546-555. [CrossRef]

91. Ong, Y.T.; Tan, S.H. Synthesis of the novel symmetric buckypaper supported ionic liquid membrane for the dehydration of ethylene glycol by pervaporation. Sep. Purif. Technol. 2015, 143, 135-145. [CrossRef]

92. Shahverdi, M.; Baheri, B.; Rezakazemi, M.; Motaee, E.; Mohammadi, T. Pervaporation study of ethylene glycol dehydration through synthesized (PVA-4A)/polypropylene mixed matrix composite membranes. Polym. Eng. Sci. 2013, 53, 1487-1493. [CrossRef]

93. Wu, J.; Lan, C.; Chan, G.Y.S. Organophosphorus pesticide ozonation and formation of oxon intermediates. Chemosphere 2009, 76, 1308-1314. [CrossRef] [PubMed]

94. Mechrez, G.; Krepker, M.A.; Harel, Y.; Lellouche, J.-P.; Segal, E. Biocatalytic carbon nanotube paper: A 'one-pot' route for fabrication of enzyme-immobilized membranes for organophosphate bioremediation. J. Mater. Chem. B 2014, 2, 915-922. [CrossRef]

95. Chen, X.; Qiu, M.; Ding, H.; Fu, K.; Fan, Y. A reduced graphene oxide nanofiltration membrane intercalated by well-dispersed carbon nanotubes for drinking water purification. Nanoscale 2016, 8, 5696-5705. [CrossRef] [PubMed]

96. Han, Y.; Xu, Z.; Gao, C. Ultrathin graphene nanofiltration membrane for water purification. Adv. Funct. Mater. 2013, 23, 3693-3700. [CrossRef]

97. Anadão, P.; Sato, L.F.; Montes, R.R.; De Santis, H.S. Polysulphone/montmorillonite nanocomposite membranes: Effect of clay addition and polysulphone molecular weight on the membrane properties. J. Membr. Sci. 2014, 455, 187-199. [CrossRef]

98. Celik, E.; Park, H.; Choi, H.; Choi, H. Carbon nanotube blended polyethersulfone membranes for fouling control in water treatment. Water Res. 2011, 45, 274-282. [CrossRef] [PubMed] 
99. Kamińska, G.; Bohdziewicz, J.; Palacio, L.; Hernández, A.; Prádanos, P. Polyacrylonitrile membranes modified with carbon nanotubes: Characterization and micropollutants removal analysis. Desalin. Water Treat. 2016, 57, 1344-1353. [CrossRef]

100. Wang, Y.; Zhu, J.; Huang, H.; Cho, H.-H. Carbon nanotube composite membranes for microfiltration of pharmaceuticals and personal care products: Capabilities and potential mechanisms. J. Membr. Sci. 2015, 479, 165-174. [CrossRef]

101. Rao, G.P.; Lu, C.; Su, F. Sorption of divalent metal ions from aqueous solution by carbon nanotubes: A review. Sep. Purif. Technol. 2007, 58, 224-231. [CrossRef]

102. Rashid, M.H.-O.; Pham, S.Q.T.; Sweetman, L.J.; Alcock, L.J.; Wise, A.; Nghiem, L.D.; Triani, G.; Panhuis, M.I.H.; Ralph, S.F. Synthesis, properties, water and solute permeability of mwnt buckypapers. J. Membr. Sci. 2014, 456, 175-184. [CrossRef]

103. Rashid, M.H.-O.; Triani, G.; Scales, N.; in het Panhuis, M.; Nghiem, L.D.; Ralph, S.F. Nanofiltration applications of tough mwnt buckypaper membranes containing biopolymers. J. Membr. Sci. 2017, 529, $23-34$. [CrossRef]

104. Pan, L.; Wang, X.; Gao, Y.; Zhang, Y.; Chen, Y.; Sun, Z. Electrosorption of anions with carbon nanotube and nanofibre composite film electrodes. Desalination 2009, 244, 139-143. [CrossRef]

105. Wang, X.Z.; Li, M.G.; Chen, Y.W.; Cheng, R.M.; Huang, S.M.; Pan, L.K.; Sun, Z. Electrosorption of ions from aqueous solutions with carbon nanotubes and nanofibers composite film electrodes. Appl. Phys. Lett. 2006, 89, 053127. [CrossRef]

106. Li, H.; Gao, Y.; Pan, L.; Zhang, Y.; Chen, Y.; Sun, Z. Electrosorptive desalination by carbon nanotubes and nanofibres electrodes and ion-exchange membranes. Water Res. 2008, 42, 4923-4928. [CrossRef] [PubMed]

107. Dumée, L.F.; Sears, K.; Schütz, J.; Finn, N.; Huynh, C.; Hawkins, S.; Duke, M.; Gray, S. Characterization and evaluation of carbon nanotube bucky-paper membranes for direct contact membrane distillation. J. Membr. Sci. 2010, 351, 36-43. [CrossRef]

108. Dumée, L.; Campbell, J.L.; Sears, K.; Schütz, J.; Finn, N.; Duke, M.; Gray, S. The impact of hydrophobic coating on the performance of carbon nanotube bucky-paper membranes in membrane distillation. Desalination 2011, 283, 64-67. [CrossRef]

109. Zhao, F.-Y.; An, Q.-F.; Ji, Y.-L.; Gao, C.-J. A novel type of polyelectrolyte complex/mwcnt hybrid nanofiltration membranes for water softening. J. Membr. Sci. 2015, 492, 412-421. [CrossRef]

110. Koenig, S.P.; Wang, L.; Pellegrino, J.; Bunch, J.S. Selective molecular sieving through porous graphene. Nat. Nanotechnol. 2012, 7, 728-732. [CrossRef] [PubMed]

111. O’Hern, S.C.; Stewart, C.A.; Boutilier, M.S.H.; Idrobo, J.-C.; Bhaviripudi, S.; Das, S.K.; Kong, J.; Laoui, T.; Atieh, M.; Karnik, R. Selective molecular transport through intrinsic defects in a single layer of cvd graphene. ACS Nano. 2012, 6, 10130-10138. [CrossRef] [PubMed]

112. Mi, B. Graphene oxide membranes for ionic and molecular sieving. Science 2014, 343, 740-742. [CrossRef] [PubMed]

113. Ying, Y.; Sun, L.; Wang, Q.; Fan, Z.; Peng, X. In-plane mesoporous graphene oxide nanosheet assembled membranes for molecular separation. RSC Adv. 2014, 4, 21425-21428. [CrossRef]

114. Hu, M.; Mi, B. Enabling graphene oxide nanosheets as water separation membranes. Environ. Sci. Technol. 2013, 47, 3715-3723. [CrossRef] [PubMed]

115. Kim, H.W.; Yoon, H.W.; Yoon, S.-M.; Yoo, B.M.; Ahn, B.K.; Cho, Y.H.; Shin, H.J.; Yang, H.; Paik, U.; Kwon, S.; et al. Selective gas transport through few-layered graphene and graphene oxide membranes. Science 2013, 342, 91-95. [CrossRef] [PubMed]

116. Han, Y.; Jiang, Y.; Gao, C. High-flux graphene oxide nanofiltration membrane intercalated by carbon nanotubes. ACS Appl. Mater. Interfaces 2015, 7, 8147-8155. [CrossRef] [PubMed]

117. Guo, J.; Liu, J.H.; Wang, L.Y.; Liu, H. Modification of ultrafiltration membranes with carbon nanotube buckypaper for fouling alleviation. Membr. Water Treat. 2015, 6. [CrossRef]

118. Bai, L.; Liang, H.; Crittenden, J.; Qu, F.; Ding, A.; Ma, J.; Du, X.; Guo, S.; Li, G. Surface modification of uf membranes with functionalized mwcnts to control membrane fouling by nom fractions. J. Membr. Sci. 2015, 492, 400-411. [CrossRef]

119. Vecitis, C.D.; Gao, G.; Liu, H. Electrochemical carbon nanotube filter for adsorption, desorption, and oxidation of aqueous dyes and anions. J. Phys. Chem. C 2011, 115, 3621-3629. [CrossRef] 
120. Duan, W.; Ronen, A.; Walker, S.; Jassby, D. Polyaniline-coated carbon nanotube ultrafiltration membranes: Enhanced anodic stability for in situ cleaning and electro-oxidation processes. ACS Appl. Mater. Interfaces 2016, 8, 22574-22584. [CrossRef] [PubMed]

121. Ronen, A.; Duan, W.; Wheeldon, I.; Walker, S.; Jassby, D. Microbial attachment inhibition through low-voltage electrochemical reactions on electrically conducting membranes. Environ. Sci. Technol. 2015, 49, 12741-12750. [CrossRef] [PubMed]

122. Dudchenko, A.V.; Rolf, J.; Russell, K.; Duan, W.; Jassby, D. Organic fouling inhibition on electrically conducting carbon nanotube-polyvinyl alcohol composite ultrafiltration membranes. J. Membr. Sci. 2014, 468, 1-10. [CrossRef]

123. De Lannoy, C.-F.; Jassby, D.; Gloe, K.; Gordon, A.D.; Wiesner, M.R. Aquatic biofouling prevention by electrically charged nanocomposite polymer thin film membranes. Environ. Sci. Technol. 2013, 47, 2760-2768. [CrossRef] [PubMed]

124. Fan, X.; Zhao, H.; Liu, Y.; Quan, X.; Yu, H.; Chen, S. Enhanced permeability, selectivity, and antifouling ability of cnts $/ \mathrm{AL}_{2} \mathrm{O}_{3}$ membrane under electrochemical assistance. Environ. Sci. Technol. 2015, 49, 2293-2300. [CrossRef] [PubMed]

125. Fan, X.; Zhao, H.; Quan, X.; Liu, Y.; Chen, S. Nanocarbon-based membrane filtration integrated with electric field driving for effective membrane fouling mitigation. Water Res. 2016, 88, 285-292. [CrossRef] [PubMed]

126. Wang, S.; Liang, S.; Liang, P.; Zhang, X.; Sun, J.; Wu, S.; Huang, X. In-situ combined dual-layer cnt/pvdf membrane for electrically-enhanced fouling resistance. J. Membr. Sci. 2015, 491, 37-44. [CrossRef]

127. Rahaman, M.S.; Vecitis, C.D.; Elimelech, M. Electrochemical carbon-nanotube filter performance toward virus removal and inactivation in the presence of natural organic matter. Environ. Sci. Technol. 2012, 46, 1556-1564. [CrossRef] [PubMed]

128. Quan, D.X.; Zhao, D.; Zhang, W.; Chen, C.; Wang, X. 2013 international symposium on environmental science and technology (2013 isest)adsorption of methyl orange dye onto multiwalled carbon nanotubes. Procedia Environ. Sci. 2013, 18, 890-895.

129. Jie, G.; Kongyin, Z.; Xinxin, Z.; Zhijiang, C.; Min, C.; Tian, C.; Junfu, W. Preparation and characterization of carboxyl multi-walled carbon nanotubes/calcium alginate composite hydrogel nano-filtration membrane. Mater. Lett. 2015, 157, 112-115. [CrossRef]

130. Khalid, A.; Al-Juhani, A.A.; Al-Hamouz, O.C.; Laoui, T.; Khan, Z.; Atieh, M.A. Preparation and properties of nanocomposite polysulfone/multi-walled carbon nanotubes membranes for desalination. Desalination 2015, 367, 134-144. [CrossRef]

(C) 2017 by the authors. Licensee MDPI, Basel, Switzerland. This article is an open access article distributed under the terms and conditions of the Creative Commons Attribution (CC BY) license (http:/ / creativecommons.org/licenses/by/4.0/). 